\title{
Beiträge zur Kenntnis des Augenzitterns der Berglente.
}

\section{Veranlagung.}

\author{
Von \\ Dr. Joh. Ohm, \\ Augenarzt in Bottrop (Westf.)
}

(Mit Unterstützung der preussischen Regierung und der rheinischen Gesellschaft für wissenschaftliche Forschung in Bonn.)

Mit 11 Kurven im Text.

\section{Einleitung.}

Das Augenzittern der Bergleute ist das klassische Beispiel einer Berufskrankheit, von der ein mehr oder minder grosser Teil der Arbeiter in Kohlengruben ${ }^{1}$ ), - nach Nieden (76, S. 43) 5,7\%, nach Dransart (175, S. 5) $12-20 \%$, nach Libert (142, S. 102) $19,2 \%$ - nach verschieden langer Arbeitszeit befallen wird. Es geht somit aus zwei Ursachen hervor, den Arbeitsbedingungen und den individuellen Verhältnissen (Veranlagung). Wenn alle Forscher auch in diesem Satze iubereinstimmen, so gehen die Ansichten über die Natur dieser Ursachen noch weit auseinander. Daraus ergibt sich, dass sie sehr verwickelter Art sein müssen. Die Prüfung aller in Betracht kommender Fragen stellt Anforderungen an Kraft und Zeit, die einem Einzelnen, besonders einem Praktiker, nichț zu Gebote stehen. Während die Feststellung der Arbeitsbedingungen mehr die Sachverständigen des Bergbaues angeht, wird es Aufgabe der Ärzte sein, das Krankheitsbild und die Veranlagung zu ergründen.

Meine Untersuchungen erstreckten sich daher zunächst auf diese beiden Punkte. Ihre sorgfältige Bestimmung wird ohne $Z_{\text {weifel unsere }}$ Aufmerksamkeit auf die Arbeitsbedingungen lenken, denen das Augenzittern seine Entstehung verdankt, wie umgekehrt die Erforschung der Arbeitsbedingungen auf den nervösen Mechanismus hinweisen muss,

1) Stassen in Lüttich hat einige leichte Fälle auch in Erzgruben beobachtet, was noch anderweitiger Nachprüfung bedarf. Vgl. anch Llewellyn (165, S. 52). 
durch dessen Störung sich das Augenzittern entwickelt. Es liegt nicht im Plane dieser Abhandlung, die Arbeitsbedingungen ausgiebig zu erörtern.

Das Augenzittern der Bergleute hat in deutschen Lehr- und Handbüchern der Augenheilkunde nur geringe Beachtung gefunden, die weder seiner praktischen Wichtigkeit in sozialer und finanzieller ${ }^{1}$ ) Hinsicht, noch seiner theoretischen Bedeutung für Physiologie, Augenund Nervenheilkunde entspricht.

Die Verhandlungen des Reichstags zum Etat des Reichsversicherungsamts rom 5. Februar 1913 und des Landtags zum Bergwerksetat vom 1. März 1913, die sich mit dem Antrag des Gewerkvereins christlicher Bergarbeiter, das Augenzittern der Bergleute der Unfallversicherung $\mathrm{zu}$ unterstellen, beschäftigten, haben die Erforschung dieses Leidens neu belebt. Soll ihr Ergebnis auch ausserhalb der Kohlenbecken Beachtung finden, so muss sie mit besseren, besonders objektiven Methoden arbeiten und mehr ins Einzelne gehen.

Die Darstellung des Augenzitterns der Berglente ist schwierig, weil es an Reichtum der Symptome wohl alle übrigen Krankheitsbilder der Augenheilkunde übertrifft. Wer ein halbes Tausend Fälle beobachtet hat, wird noch immer durch neue Züge überrascht. Man muss sich aber hüten, aus wenigen Beobachtungen weitgehende Schlïsse zu ziehen. Denn es ist angesichts der überwältigenden Fülle der Eigenschaften schwer, das Wesentliche festzustellen. Vorderhand wird darum die häufige Einflechtung von Einzelbefunden noch nicht zu entbehren sein.

Die folgende Abhandlung ist das Ergebnis einer sechsjährigen, an einem reichen Material geführten Untersuchung. Dank besseren Methoden war ich in dex Lage, meine erste, vor drei Jahren ansgearbeitete Darstellung des Augenzitterns in vielen Punkten zu vertiefen und zu erweitern und ron manchen Fehleru, die zunächst noch unterlaufen sind, zu befreien. Für die von der preussischen Regierung und der rheinischen Gesellschaft für wissenschaftliche Forschung in Bonn gewährte reiche Unterstützung danke ich auch an dieser Stelle bestens.

\section{Übersicht über đie Zahl der Fälle.}

Meine augenärztliche Tätigkeit bei der Bochumer Knappschaft begann Mitte 1908. Die meisten Fälle beobachtete ich 1909. Seitdem sinkt die Zahl allmählich. Die Kranken wohnen zum grössten Teil

1) Llewellyn (165) schätzt die in England durch das Augenzittern jährlich verursachten Kosten auf zwei Millionen Mark. 
in Bottrop (Schächte der Arenbergschen Altiengesellschaft und des Fiskus) zum kleineren Teil in Borbeck (Schächte Christian Levin, Neucöln, Carolus Magnus des Essener Bergwerkvereins) und Osterfeld (Schächte der Gute-Hoffnungs-Hütte). Die Berechnung des Verhältnisses der Kranken zu der Belegschaft unter Zugrundelegung meines Beobachtungsmaterials würde noch kein genanes Bild der Häufigkeit des Augenzitterns ergeben, weil die Belegschaft obiger Zechen sich auf mehrere Augenärzte verteilt. Eine nicht unbeträchtliche Zahl kam nicht wegen des Augenzitterns, sondern aus andern Gründen, z. B. wegen einer Brille oder Entzündung oder Verletzung zu mir.

Die Zahl der beobachteten Fälle von Augenzittern betrug:

$\begin{array}{lr}1907 & 1 \\ 1908 & 100 \\ 1909 & 162 \\ 1910 & 154 \\ 1911 & 134 \\ 1912 & 77 \\ 1913 & 62 \\ 1914 \text { (erstes Halbjahr) } & 57 \\ & \text { Summa } \\ & 747\end{array}$

Es ist klar, dass nicht jeder einzelne nach allen in Betracht kommenden Gesichtspunkten untersucht werden konnte, denn eine eingehende Untersuchung erfordert mehrere Stunden.

\section{Die Veranlagung.}

Der grösste Teil der Bergleute bleibt auch bei jahrzehntelanger Fortsetzung der Grubenarbeit dauernd frei von Augenzittern. Andere werden schon sehr frühzeitig befallen. Die kürzeste Inkubationszeit, die ich bis jetzt beobachtete, betrug $\left.2^{3}\right|_{4}$ Jahre. Ungefähr die Hälfte aller Augenzitterer erkrankt vor Ablauf von fünfzehn Jahren der Grubenarbeit (160, S. 56). Die früh von stärkerem Augenzittern befallenen Bergleute befinden sich in einer üblen Lage. Unterbrechung der Grubenarbeit für ein bis zwei Jahre hat zwar Genesung zur Folge. Aber nach Rückkehr unter die alten Bedingungen lässt der Rückfall in der Regel nicht lange auf sich warten. Es ist daher sehr wünschenswert, die zu frühzeitigen Augenzittern neigenden Menschen erkennen zu können, um sie vor dem bergmännischen Beruf zu bewahren. Nur eine sorgfältige körperliche Untersuchung und kritische Betrachtung kann über diesen vielumstrittenen Punkt Klarheit schaffen. Folgende Punkte wurden von mir bis jetzt berücksichtigt. 


\section{Die Nationalität.}

Der stets sich steigernde Bedarf an Arbeitskräften hat im RuhrLippe-Kohlenbecken eine starke Einwanderung gezeitigt. Die meisten stammen aus den slawischen Bezirken im Osten Preussens, andere aus Österreich, Holland, Italien. Nach den Hausnamen zu urteilen, waren von meinen Kranken:
1. 342 Deutsche
$45,7 \%$,
2. 400 Slawen (hauptsächlich Polen) $53,5 \%$,
3. 3 Holländer
4. 2 Italiener
$0,4 \%$
$0,3 \%$.

\section{7}

Da in Bottrop das Verhältnis der Deutschen zu den Polen gleich $3: 1$ ist, so überwiegen unter den Augenzitterern die Polen in hohem Grade.

\section{Der Allgemeinzustand.}

Auf Grund einer eingehenden körperlichen Untersuchung werden nur gesunde, arbeitsfähige Leute zur Grubenarbeit zugelassen. Bei den Augenzitterern findet man verschiedene körperliche Beschaffenheit: schwächliche, mittelstarke und auch viele ausserordentlich kräftige Menschen.

Der Meinung mancher Ärzto, das Augenzittern sei eine Folge von Blutarmut oder einer allgemeinen Neurose (Rutten, 139), kann ich mich nicht anschliessen. Natürlich ist nicht jeder Augenzitternkranke im übrigen kerngesund; aber ich meine, dass bei den meisten sich andere Krankheitszeichen nicht nachweisen lassen, und dass sie sich selbst auch für vollständig gesund halten. Ob im Gefolge von schwächenden Allgemeinkrankheiten sich eher Augenzittern entwickelt oder bestehendes verschlimmert, lässt sich nicht auf Grund weniger Einzelbeobachtungen oder der Aussagen der Kranken, sondern nur an einem grossen Krankenhausmaterial entscheiden. Mir fehlen für diesen Punkt die nötigen Unterlagen.

\section{Die Körpergrösse.}

Die geringe Höhe der Kohlenflötze und Querschläge muss uns nötigen, auch die Körpergrösse, die zugleich auch ein Anhaltspunkt für die körperliche Kraft ist, in Betracht zu ziehen. Ich habe zuerst $(160$, S. 77) eine Statistik über die Grösse von 101 Bergleuten mit Augenzittern gebracht und will sie in folgendem erweitern. 
Die Körpergrösse, ohne Schuhe gemessen, betrug:

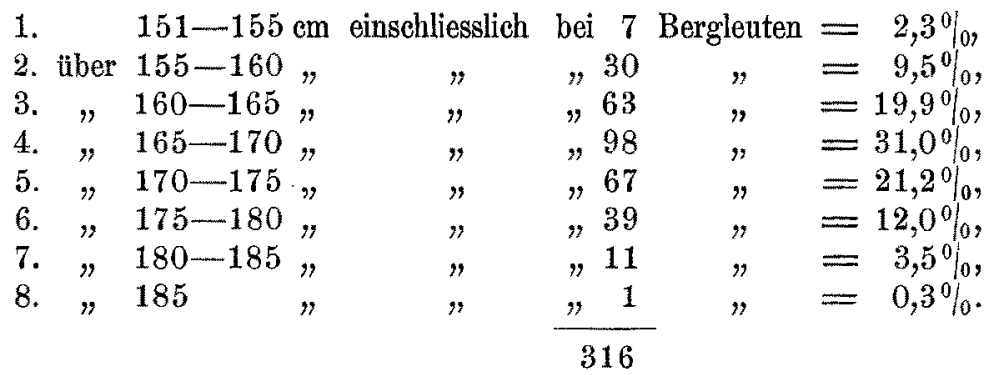

Der Kleinste war 151, der Grösste 187,5, der Durchschnitt $168,3 \mathrm{~cm}$. Diese Ziffern enthalten starke Gegensätze, die erst in Gemeinschaft mit andern Zeichen besprochen werden sollen. Bei der Schilderung der Symptome des Augenzitterns werden feine Beziehungen. zwischen Grösse und einzelnen Eigenschaften des Augenzitterns nachgewiesen werden.

\section{Alkoholismus.}

Von den Revierärzten, welche die Bergleute aus grösserer Nähe in ihren persönlichen und häuslichen Verhältnissen beobachten können, als wir Augenärzte, haben mir einige, z. B. Herr Dr. Heger in Bottrop, die Meinung ausgesprochen, dass übermässiger Alkoholgenuss bei der Entstehung des Augenzitterns eine wichtige Rolle spielt. Die Mehrzahl der Augenzitterer geniesst regelmässig Schnaps oder Bier. Im Laufe einer längeren Beobachtung kann man genïgend Beweise dafür sammeln. Auch kommen uns oft Klagen der Ehefrau oder sonstigen Umgebung des Kranken zu Ohren. Es scheint mir auf Grund meiner persönlichen Erfahrung ziemlich aussichtslos, durch Befragen die verbrauchte Alkoholmenge ermitteln zu wollen. Sicher ist aber, dass besonders unter den älteren Augenzitterern manche Trinker sind, weshalb ich in meiner ersten Abhandlung das Zittern des Kopfes, der Hände und des übrigen Körpers, an dem manche Augenzitterer leiden, auf den Alkoholismus zurïckgeführt habe. Butler (170) hat dies bestritten; doch glaube ich, diese Behauptung auch jetzt noch für viele Fälle aufrecht halten zu dürfen, wenn auch nicht zu leugnen ist, dass gewisse Kopfbewegungen einen näheren Zusammenhang mit dem Angenzittern haben. Der Alkohol scheint mir aber doch keine conditio sine qua non unter den Ursachen des Augenzitterns zu sein, denn ich fand unter den Augenzitterern auch einzelne Abstinenten und viele offenbar mässige Leute. Es wird später erörtert werden, welche Teile des Nervenmuskelapparates der Alkohol angreift. 


\section{Der Augenbefund.}

Naturgemäss haben die Arzte auf der Suche nach der Ursache des Augenzitterns von jeher ihre Aufmerksamkeit auf den Zustand der Augen gerichtet. Trotz mehr als fünzigjähriger Aussprache ist aber bis jetzt eine leidliche Übereinstimmung in der Bewertung der verschiedenen Augenfehler nicht erzielt worden. Ich will deshalb auf diesen Punkt jetzt ausführlicher als in meiner ersten Arbeit eingehen.

a) Aussere und innere Augenkrankheiten.

Die ärztliche Untersuchung, der sich die angehenden Bergleute zu unterziehen haben, erstreckt sich im allgemeinen nur auf das Aussere der Augen. Leute mit akuten und chronischen Entzündungen und solche, die sich auf Befragen als sehschwach bezeichnen, werden abgelehnt. Einäugigkeit and Schielen bilden keinen Grund für die Zurückweisung. So kommt es, dass der grösste Teil der Bergleute über gute Augen verfügt, wenn auch hier und da mal einer mit schlechteren Augen durchschlüpft.

Die bergmännische Arbeit, besonders die der Pferdetreiber, Schlepper, Kohlenhauer, scheint mir keine erheblichen Anforderungen an die Sehkraft zu stellen. Ich habe nicht selten Leute beobachtet, die bei ganz mangelhaften Augen jahrzehntelang den Dienst in der Grube versehen haben. Einer z. B. mit einer Kurzsichtigkeit des rechten Auges von $18 \mathrm{D}$, des linken von $22 \mathrm{D}$, war 19 Jahre lang Kohlenhauer, und zwar ohne je eine Brille getragen zu haben, womit natürlich nicht gesagt sein soll, dass derartig sehschwache Leute in die Grube gehören. Eher setzt noch die Tätigkeit der Zimmerhauer oder Reparaturhauer oder Wettermänner gute Augen voraus.

An äusseren Augenkrankheiten beobachtete ich bei den Augenzitterern ein- oder beiderseitige Maculae corneae (ganz feine Flecken sind nicht in Betracht gezogen) $11 \mathrm{mal}$, Leucoma adhaerens $5 \mathrm{mal}$ (1 mal mit guter, 1 mal mit herabgesetzter Sehschärfe, 3 mal mit Blindheit) Trachom $7 \mathrm{mal}$, Dystrophia corneae $1 \mathrm{mal}$, Keratitis parench. luet. 1 mal. Fälle von angeborenem Augenzittern und Schielen werden später berücksichtigt.

Von inneren Krankheiten fand sich grauer Star $3 \mathrm{mal}$ (1 mal ohne Lichtschein, $1 \mathrm{mal}$ mit Projektion, $1 \mathrm{mal}$ mit Fingerzählen), Schichtstar $1 \mathrm{mal}$, Trübung der hinteren Kapsel 1 mal (beide mit mangelhafter Sehschärfe), Synchysis scintillans (bei guter Sehschärfe), Glaskörpertrübung und Sehnervenveränderungen ( $S=$ Handbewegung) 
1 mal, Chorioretinitis beiderseits 2 mal (mit schlechter Sehschärfe) und einseitig $1 \mathrm{mal}$ ( $S=$ Finger in $1 \mathrm{~m}$ ), Stauungspapille $1 \mathrm{mal}$.

Die Unfallverletzungen werden später gesondert behandelt.

Berücksichtigt man, dass diese Fälle die gesamte Ausbeute unter einem Material von 747 Fällen von Augenzittern darstellen, und dass bei manchen die Entstehung des Augenzitterns dem Auftreten des genannten Augenleidens noch voran ging, z. B. bei den Fällen von grauem Star, Stauungspapille, einer beiderseitigen Chorioretinitis, so muss man den Schluss ziehen: Innere und äussere Krankheiten der Augen kommen nur bei einem so kleinen Bruchteil der Fälle ror, dass ihnen unter den Ursachen des Augenzitterns keine erhebliche Bedeutung beizumessen ist.

b) Unfälle.

$\mathrm{Zu}$ den Ursachen des Augenzitterns gehört nach Dransart(96) auch der Unfall, und zwar nicht nur ein solcher allgemeiner Art, besonders des Schädels, sondern auch die leichten, alltäglichen Verletzungen der Bindehaut und der Hornhaut. Dransart stellt sich den Zusammenhang nicht so vor, dass Augenzittern wirklich dadurch erzeugt werde, sondern so, dass manifestes Zittern verschlimmert und latentes (ganz geringes Zittern obne subjektive Beschwerden) in manifestes umgewandelt wird. Er glaubt, auch den einseitigen Nystagmus durch Verletzung dieses Auges erklären zu können. Nuel (96) und Llewellyn(165) schlossen sich ihm an, Romiée(142) widersprach. Llewellyn führt Verletzungen der Hornhaut, des Schädels, des Rückens, eine Fingeramputation und einen Beinbruch als auslösende Ursache an.

Die Beweisführung stützt sich einzig auf die Angabe der Kranken. Wenn aber irgendwo, so genügt sie in dieser, in jeder Beziehung dunklen Sache nicht. Auch der Umstand, dass der Kranke erst beim Arzt auf seinen Nystagmus aufmerksam wird, reicht nicht hin. Ich habe z. B. gelegentlich einer Brillenbestimmung manchen deutlichen Nystagmus festgestellt, von dem der Betreffende keine Ahnung haben wollte. Ein Bergmann, der arbeiten will, gibt nicht gern zu, dass er an Augenzittern leidet, oder er stellt es als harmlos hin. Die Frage, ob Augenverletzungen Nystagmus hervorrufen können, habe ich vor kurzem auf Grund eines Materials von 1197 Augenverletzungen ausführlich behandelt (198, S. 47-49) und will hier nur das Ergebnis mitteilen. Man darf sich nicht darauf beschränken, bei einem Nystagmus nach einem früheren Unfall zu fahnden, sondern man muss auch den andern Weg gehen, nämlich das Schicksal der Unfallverletzten dahin zu verfolgen, ob sich 
bei ihnen später Nystagmus entwickelt. Ein positives Resultat dieser Nachforschungen würde eine viel kräftigere Stütze für die Dransartsche Behauptung sein, als die Angaben der Kranken. Deshalb schrieb ich $(198$, S. 48$)$ :

„Wenn es wahr wäre, dass latentes Zittern durch so geringfügige Unfälle in manifestes umgewandelt und letzteres verschlimmert würde, so dass also diese Bergleute gezwnngen würden, die Arbeit aufzugeben, so müsste man erwarten, dass ein grösserer Teil der Bergleute, die mit Verletzungen unsere Hilfe nachsuchen, später mit Augenzittern zu uns zurückkehrten. Man müsste ferner erwarten, dass dies entweder während der Heilung der Unfallfolgen oder doch bald nachber geschähe. Denn es wäre nicht einzusehen, warum eine so kleine Veränderung, wie sie z. B. ein Hornhantfremdkörper am Auge nach Monaten oder Jahren zurücklässt, ein so tief in alle Innervationsverhältnisse des Auges eingreifendes Leiden wie das Augenzittern nach sich ziehen sollte. Diese Probe aufs Exempel versagt völlig. Von den 1197 Unfallverletzten, die ieh in diesen 5 Jahren (1908-1913) behandelt habe, und die infolge ihrer Arbeitsbedingungen zum grössten Teil dem Augenzittern ausgesetzt waren, kamen nur zwei später wieder mit Augenzittern $\mathrm{zu}$ mir."

Das ist sogar weniger, als man hätte erwarten sollen, auch wenn der Nystagmus nichts mit Unfällen zu tun hat.

Einseitiges Zittern lässt sich schon gar nicht durch Augenunfälle begründen, weder statistisch, noch theoretisch. Darüber später.

Die Frage, ob schwere Schädelverletzungen an der Entstehung des Augenzitterns der Bergleute Anteil haben, muss ich noch unentschieden lassen. Auch hier beweist ein einzelner Fall gar nichts. Solange die Lösung des Augenzitternproblems noch nicht weiter gediehen ist, als jetzt, kann diese Frage nur durch die statistische Methode geklärt werden, und zwar so, dass man an einem grösseren Krankenhaus alle schweren Verletzungen auf die Entstehung des Angenzitterns längere Zeit verfolgt.

c) Die Sehschärfe der Augenzitterer.

Nach Llewellyn, der ein grosses Material gut durchgearbeitet hat (165, S. 91-92), ist die Sehschärfe selten normal bei einem, der viele Jahre untertage zugebracht hat. Bei Nystagmus soll sie deutlich vermindert sein. Er hält geradezu die Sehschärfe für ein Mittel, die Schwere des Augenzitterns abzuschätzen. Unter 499 Fällen fand er nur 64 mal normale Sehschärfe und $255 \mathrm{mal}{ }_{1 / 3}$ und weniger.

Bei der Prïfung der Sehschärfe der Augenzitterer ist streng zu unterscheiden zwischen der Sebschärfe zurzeit des Zitterns und der Ruhe. Während des Zitterns ist die Sehschärfe immer herabgesetzt, und 
in verschiedenem Masse, entsprechend der Art des Zitterns (Schwingungsrichtung, Amplitude, Zahl). Sie wird uns später beschäftigen. Hier kommt es zunächst auf die Sehschärfe während der Ruhe an, die auch Llewellyn gemessen hat. Selbst bei den schlimmsten Fällen von Augenzittern gelingt es meistens durch Rückwärtsbeugung des Kopfes und starke Senkung des Blickes die Augen zum Stehen zu bringen. In andern Fällen wurde die Sehschärfe im Stadium der Genesung, bei einzelnen auch später ermittelt.

Folgende Tabelle gibt die Sehschärfe des besten Auges auf Zimmerlänge während der Augenruhe, ohne Glas, wie sie bei der Arbeit in Betracht kommt.

$$
\begin{aligned}
& \text { 1. Von } 1-5 / 6(4 / 5) \text { bei } 372 \text { Fällen }=71,1 \% \text {, } \\
& \text { 2. unter } 5 j_{8}\left(f_{5}\right)-\left.1\right|_{2} " 72 "=13,7 \% \text {, } \\
& 3 .\left." 1\right|_{2}-\left.1\right|_{10} ", 54 "=10,30 \% \text {, } \\
& \text { 4. " } 1 / 10 \text { " } " 25 "=4,8 \% \text {. }
\end{aligned}
$$

Die Sehschärfe der Augenzitterer ist demnach eine durchaus gute. Nur $15 \%$ haben weniger als halbe Sehschärfe. Ich kann mich also den Ärzten (Dransart, Nuel), die den Augenzitterern im allgemeinen eine gute Sehschärfe zusprechen, durchaus anschliessen.

d) Die Refraktion.

Browne und Ross Mackenzie (158, 1912), die 100 Fälle statistisch verwerteten, und dabei $90 \%$ Refraktionsfehler fanden (darunter $48 \%$ mitmyopischem, hypermetropischem oder gemischtem Astigmatismus, $27 \%$ mit Hypermetropie, $15 \%$ mit Myopie) halten Refraktionsfehler für eine der Ursachen des Augenzitterns. Ich fand bei 532 Augenzitterern:

1. Emmetropie bei 137 Fällen $=25,7 \%$,

2. Hypermetropie, bzw. Astigmatismus " $240 "=45,1 \%$, darunter: a) bis $0,5 \mathrm{D}$ bei 92 Fällen $=17,3 \%$,
b) $\geq 0,5-1,0 D, 75, n=14,1 \%$,
c) $>1,0-2,0 ", 37 ",=6,9 \%$,
d) $>2,0-3,0 ", 15 \quad,=2,8 \%$,
e) $>3,0-5,0, " 16, "=3,0 \%$,
f) $>5,0-7,0 "$ " 5 " $=0,9 \%$.

3. Myopie bzw. Astigmatismus bei 82 Fällen $=15,4 \%$, darunter: a) bis $0,5 \mathrm{D}$ bei 8 Fällen $=1,5 \%$,

b) $>0,5-1,0 D, 15 \Rightarrow=2,8 \%$,

c) $>1,0-2,0, " 23 \quad,=4,3 \%$,

d) $>2,0-3,0, " 4, "=0,8 \%$,

e) $>3,0-5,0,7,7 \Rightarrow=1,3 \%$,

f) $>5,0-10,0, " 15 "=2,8 \%$,

จ. Graefe's Archir für Ophthalmologie. LXXXIX. 3. 

g) $>10,0-15,0 D$ bei 7 Fällen $=1,3 \%$,
h) $>15,0-22,0, " 3,=0,6 \%$.
4. Anisometropie
bei 73 Fällen $=13,7 \%$.

Zur Erläuterung sei bemerkt, dass unter 2. und 3. sowohl die sphärische als die astigmatische Ametropie verzeichnet ist. Kamen beide an einem Auge zusammen vor (Astigmat. compos.), so habe ich die Dioptrienzahl beider addiert. Waren beide Augen im bezug auf die Ametropie der gleichen Art verschieden, so wurde jedesmal das schlimmere Auge in die Statistik eingesetzt. Unter 4. sind die Fälle von Kombination von 1 . bis 3 . eingereiht.

Aus dieser Statistik geht zunächst hervor, dass die Zahl der Ametropen (fast $75 \%$ ) die der Emmetropen (25\%) weit übertrifft. $\mathrm{Ob}$ Refraktionsfehler bei der Erzeugung des Augenzitterns positiv mitwirken, ist damit aber noch nicht bewiesen. Denn es fragt sich zunächst, wie die Refraktionsstatistik der Bergleute im allgemeinen aussieht, worüber bis jetzt noch keine Erhebungen angestellt sind. Nach der Herruheiserschen Tabelle (siehe Hess, Die Anomalien der Refraktion und Akkommodation des Auges) sind von 30 Jahre alten Menschen 28\% emmetrop, 57\% hypermetrop, $15 \%$ myop. Die Anisometropie ist dabei nicht berücksichtigt. Meine Statistik entfernt sich also nicht weit von der Herrnheiserschen.

Streng genommen, würde die Frage nach der ursächlichen Bedeutung der Brechungsfehler in der Pathologie des Augenzitterns folgendermassen lauten: Wieviele Augenzitterer sind unter 100 Emmetropen und unter 100 Ametropen der gleichen Art unter sonst gleichen Bedingungen (was ja auch für die übrigen Fehler gilt)? Die Bearbeitung in dieser Hinsicht würde sich nur an einer nach Tausenden zählenden Belegschaft verwirklichen lassen.

Aus obiger Statistik ergibt sich aber als sicher, dass die Zahl der Emmetropen gross genug ist, um die Frage nahe zu legen: Woher rübrt denn bei ihnen das Augenzittern? Ferner sind bei den Ametropien die geringen Grade vorherrschend. Hypermetropie und Myopie bis zu $1 D$ können in Anbetracht der groben Grubenarbeit kaum eine Rolle spielen, und grössere Fehler über $3 D$ sind mit 53 $(=10 \%$ ) ganz in der Minderheit.

Es lässt sich auch keine Beziehung der Refraktion und Sehschärfe zu der Schwere, Schwingungsrichtung, Zahl usw. des Augenzitterns feststellen. Ebenso wie es unter den Emmetropen ganz schlimme Fälle von Augenzittern gibt, sind unter den hohen Graden von Hypermetropie (über $5-7 D$ ) und Myopie $(10-22 D$ ) ganz leichte. 
Ergebnis: Die durchschnittlichen Sehwerte und Refraktionsverhältnisse der Augenzitterer liegen zu günstig, als dass sie einen wichtigen Platz unter den Ursachen des Augenzitterns beanspruchen können. Ob eine Herabsetzung der Sehschärfe auf $1 / 10$ und weniger die Entstehung des Zitterns begünstigte, lasse ich noch dahin gestellt ${ }^{1}$ ). Ich komme bei anderer Gelegenheit noch darauf zurück. Jedenfalls ist die Forderung Llewellyns [citiert bei Court(167)]: "no man with error of refraction should work underground" weder praktisch durchführbar, noch theoretisch begründet.

e) Die Akkommodation.

Das Akkommodationsvermögen der Augenzitterer hält sich in normalen Grenzen. Die Tätigkeit des Hauers vollzieht sich auch in hinlänglicher Entfernung, um an die Akkommodation keine besonderen Anforderungen zu stellen, so dass sie für die Entstehung des Augenzitterns nicht in Frage kommt.

f) Der Lichtsinn.

Eine fast regelmässig wiederkehrende Klage des Bergmanns mit Augenzittern bezieht sich auf die Minderwertigkeit seines Sehens im Dunkel der Grube, in der Dämmerung und selbst bei nebeligem Wetter. Dadurch wurde die Aufmerksamkeit der Forscher schon friih auf den Lichtsinn gelenkt, und Nieden (5) ist der erste gewesen, der schon 1872 den Nystagmus der Bergleute mit Hemeralopie in Verbindung gebracht hat.

Später haben die Autoren ihr Vorkommen z. T. bejaht, z. T. verneint. Einwandsfreie Untersuchungen fehlten aber bis in die jüngste Zeit, was verwunderlich ist, da gerade das Problem des Lichtsinns den zahlreichen Arzten, die den Nystagmus einzig und allein auf die mangelhafte Grubenbeleuchtung zurückführen, besonders nahe hätte liegen sollen. Es ist das Verdienst von Weekers (115), diese Frage mit Hilfe des Nagelschen Adaptometers im Laboratorium der Lütticher Universität in Angriff genommen zu haben (1910). Er kommt zu dem Ergebnis, dass in gewissen Fällen von gutartigem Nystagmus die Adaptation sich in normalen Grenzen hält, dass aber in der Mehrzahl der Fälle eine Störung des Lichtsinns rorhanden ist. Die Adaptationskurve kriecht, anstatt sich während der ersten 10 Minuten zu erheben, 20-25 Minuten an der Abszisse, um dann regelmässig und

1) Derartige Leute sind auch aus sonstigen Gründen nicht zur Grubenarbeit zuzulassen. 
progressiv zu steigen und normale oder fast normale Höhe zu erreichen. In andern Fällen steigt die Kurve 30 oder 40 Minuten langsam, um dann plötzlich auf grosse Höhe zu gelangen. In den schlimmsten Fällen vollzieht sich die Hebung zögernd, und es wird nur ein niedriges Niveau erklommen.

Der niedrigste Wert liegt bei Weekers bei 36000 reduzierten Empfindlichkeitswerten. Weekers hat keinen Parallelismus zwischen Intensität der Zuckungen und Störungen der Adaptation gefunden, aber wohl häufig Beziehungen zwischen letzterer und den Klagen der Kranken. Die mangelhafte Adaptation kann unter Umständen das Krankheitsbild beherrschen und lebhafte Klagen hervorrufen. Weekers vermag auf die Frage nach dem Zusammenhang zwischen Adaptationsstörung und Augenzittern keine Antwort zu geben.

Da die Untersuchungen von Weekers die einzigen mit exakter Methode unternommen bisher geblieben sind, so wird es nötig sein, ausführlich auf diesen Punkt einzugehen. Beror ich aber meine Resultate mitteile, muss ich den modernen Stand der Lehre des Lichtsinns, soweit er für die Pathologie des Augenzitterns von Wichtigkeit ist, kurz darlegen.

Allgemeines über den Lichtsinn. Der doppelten anatomischen Gliederung der Empfangsapparate der Netzhaut in Zapfen und Stäbchen entspricht nach der Duplicitätstheorie eine verschiedene physiologische Funktion. Die Zapfen dienen dem Sehen im hellen Tageslicht (Hellapparat), die Stäbchen dem Sehen bei herabgesetzter Beleuchtung (Dämmerungsapparat). Thre Tätigkeit rollzieht sich nach Behr (135) zeitlich getrennt. Die Zapfen empfinden qualitative (Farben) und quantitative, die Stäbchen nur quantitative Unterschiede (farbenblind). Beide sind fähig, sich an wechselnde Lichtmengen anzupassen (Adaptation), die Stäbchen in viel höherem Grade als die Zapfen. Die Adaptation der Stäbchen ist an die Gegenwart von Sehpurpur gebunden. Sie verläuft nach regelmässigen Gesetzen. Nach guter Helladaptation steigt die Empfindlichkeit der Zapfen bei Dunkelaufenthalt gemäss den Untersuchungen von $\mathrm{Nagel}$ und Schäfer bis zur 6. Minute auf das 16 fache, nach Behr(135) auf das 200 fache des Anfangswertes.

Die genaue Erforschung der Adaptation der Stäbchen ist das Werk Piepers. Nach Helladaptation ist die Steigerung ihrer Empfindlichkeit in den ersten 10 Minuten ganz gering, um in den nächsten $30-40$ Minuten ganz gewaltig $(8000 \times$ und mehr) zu wachsen und dam die exreichte Höhe beizubehalten. 
Fig. 1 gibt eine mit dem Nagelschen Apparat aufgenommene normale Adaptationskurve (140).

Die binokulare Adaptation ist nach Pieper fast doppelt so gross wie die monokulare, ein Unterschied, der sich aber erst nach einem Dunkelaufenthalt von etwa 30 Minuten herausbildet. (Gesetz der binokularen Reizaddition.)

Das Maximum der Empfindlichkeitszunahme im Dunkeln liegt nicht in der Fovea, sondern in einem sie umgebenden, $15-20^{\circ}$ breiten Ring, so dass dieser in der Dunkelheit die beste Sehschärfe besitzt.

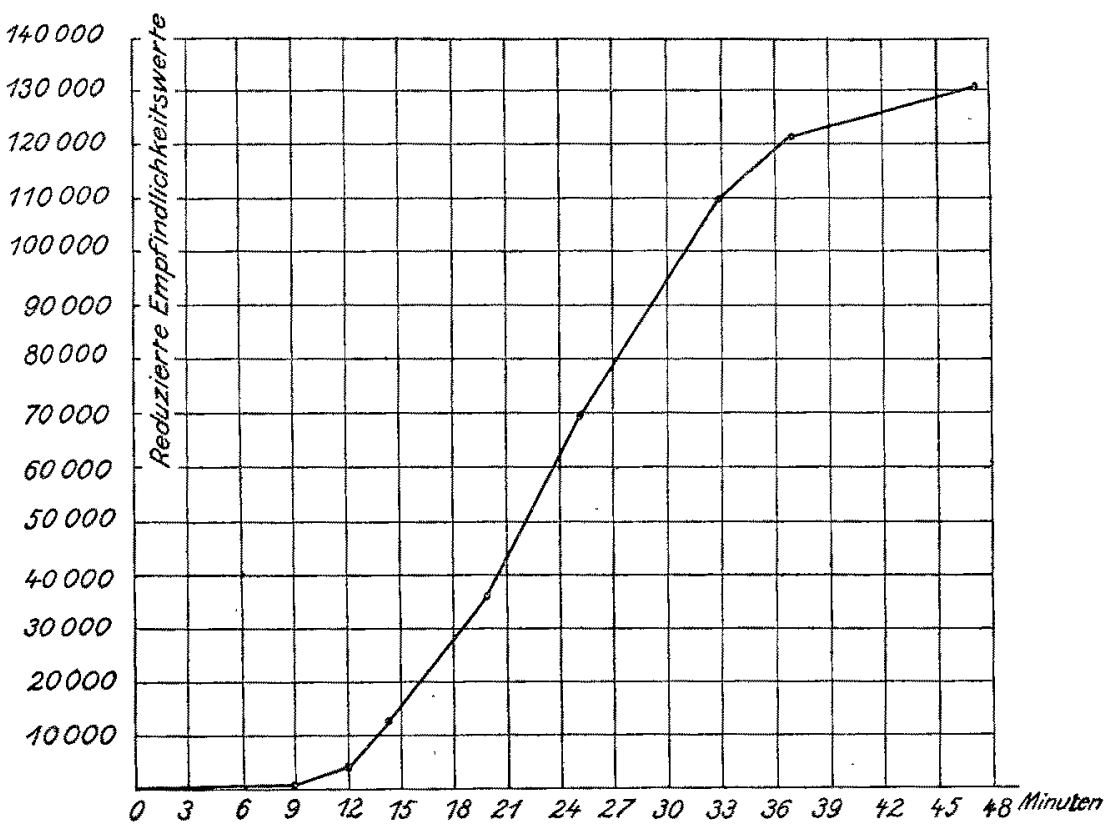

Fing. 1.

Die Adaptationskurve ist bei derselben Person, gute Helladaptation vorausgesetzt, ziemlich konstant. Wichtig ist aber, dass grosse physiologische individuelle Unterschiede vorkommen, was die Schnelligkeit und Höhe der Adaptation angeht. Nach Stargardt (132), dem ich jetzt folge, ist die Adaptation jedem Menschen in verschiedenem Grade angeboren. Andere. Eigenschaften, die die Adaptationskurve beeinflussen, sind: das Lebensalter, Refraktionsfehler, Krankheiten des Auges und seiner nervösen Bahnen im Gehirn. Während die Kurve sich in der Jugend schnell auf grosse Höhe hebt, erreicht sie im Alter nur zögernd ein niedriges Niveau (Weekers, Piper, Tschermak, Stargardt). Die Altersunterschiede werden von Wölfflin geleugnet. Em- 
metropie, Hypermetropie selbst hohen Grades, Pigmentierung der Augen haben nach Stargardt keinen Einfluss auf den Lichtsinn. Störungen der Dunkeladaptation finden sich nach Stargardt bei Myopie mit Hintergrundsveränderungen, gemischtem Astigmatismus und manchen andern Augenkrankheiten, die ich übergehen kann, da sie bei den Augenzitterern keine nennenswerte Rolle spielen. Horn (123) teilt einen Fall von sehr niedriger Adaptationskurve bei einem 59 jährigen Alkoholiker mit (nach 60 Minuten ungefähr 10 reduzierte Einheiten).

Bei dieser Gelegenheit möchte ich erwähnen, dass in hiesiger Gegend im Frühjahr bei Kindern und jungen Leuten eine Störung der Adaptation in Verbindung mit Xerose der Bindehaut (darin zahlreiche Xerosebacillen) in wechselnder Häufigkeit auftritt.

Der Lichtsinn der Augenzitterer. Wenn ein Bergmann aus dem hellen Tageslicht mit einer Lampe von 1,5 Kerzenstärke in das Dunkel der Grube, deren Wände nur einen kleinen Teil des Lichtes zurückwerfen, hinabsteigt, so finden in seinem Sehorgan folgende Vorgänge statt: Zu Anfang völlige oder fast völlige Unempfindlichkeit gegen das diffus reflektierte licht der Wände usw.; in den ersten 5 Minuten Steigen der Empfindlichkeit der Zapfen um das 200 fache; nach 10 Minuten Beginn der Empfindlichkeitszunahme der Stäbchen, die nach 30-40 Minuten sehr beträchtlich wird und dann ziemlich gleich bleibt. Die Forea centralis ist für die meisten Lichtreize, abgesehen von der Flamme und dem von hellen Gegenständen, z. B. Körperteilen, kommenden oder von den Kohlefacetten gespiegelten Licht unterschwellig. Das Maximum der Sehschärfe für das iübrige Licht liegt in der Umgebung der Forea. Hinzu kommt noch die Unempfindlichkeit gegen Farben und eventuell eine Störung der Fusion infolge der geringen Helligkeit der Netzhautbilder, die bis jetzt meines Wissens noch nicht erforscht ist. Alle diese Dinge verdienen unsere Aufmerksamkeit. Ich untersuchte zunächst den Lichtsinn der Augenzitterer.

\section{Untersuchungsmethode.}

Benutzt wurde das Adaptometer von Nagel (140). Da es hier auf Massenuntersuchungen ankommt, so war es nicht möglich, Zeit und Personen so zu wählen, dass zu Beginn der Untersuchung immer volle Helladaptation vorhanden war. Die Prüfung geschah vielmehr ohne Rücksicht auf die Tages- und Jahreszeit, so wie die Leute in die Sprechstunde kamen. Die Anfangsschwelle kann daher von Fall zu Fall, weil unter verschiedenen Bedingungen gemessen, nicht verglichen werden. Da aber nach Piper und Nagel (140, S. 15) ohne Rücksicht auf die vorhergehende Belichtung nach $30-45$ Minuten 
ein konstanter Wert erreicht wird, so wurde zum Vergleich die Kurvenhöhe gewählt, die nach 60 Minuten im Dunkelanfenthalt erzielt war. Die Kurve wird in relativen Empfindlichkeitswerten R. E. (Nagel) ausgedrückt. Das Verhältnis der relativen zu den von Weekers und andern verwandten reduzierten Empfindlichkeitswerten ist fast gleich $2: 1$. Die Prüfung geschah immer binokular in $57 \mathrm{~cm}$ Entfernung. Die beleuchtete Milchglasscheibe lag etwas unterhalb der Horizontalen, weil dabei am ersten Ruhe der Augen gewährleistet wird. Manche litten auch während der Untersuchungen an Zittern. Was die Frage angeht, ob der Nystagmus das Ergebnis der Prüfung ungünstig beeinflusst, so ist daran zu erinnern, dass die Netzhaut für bewegte Reize empfindlicher ist als für stehende. Starkes Zittern wird aber wohl ungïnstig auf die Aufmerksamkeit wirken. Auch ist es häufig mit Lidbewegungen verbunden, die die Beobachtung stören müssen. Etwas oberhalb der Milchglasplatte war die rote Nagelsche Fixiermarke angebracht. Manche wurden dadurch jedoch, besonders wenn die Lichtreize ganz schwach wurden, eher behindert. Bei der Bestimmung der Reizschwelle ging ich so vor, dass ich die Beleuchtung der Milchglasplatte allmählich verringerte, bis nichts mehr gesehen wurde („dunkel"). Dann verstärkte ich das Licht wieder, bis "hell", gesagt wurde. Dieser letztere Wert wurde gemäss dem Beispiel Stargardts vermerkt, nachdem ich mich mehrere Male durch $\mathrm{Ab}$ - und Zudecken der Milchglasplatte mit der Hand von der Zuverlässigkeit der Angaben uiberzeugt hatte, was unbedingt erforderlich ist. In der Stunde fanden $4-5$ Messungen statt.

Die gefundenen Werte sind niedriger als die früherer Forscher. Die Lichtsinnprüfung scheint mir besonders für ungeübte Beobachter nicht leicht zu sein, und der Genauigkeit unserer sonstigen Methoden zu entbehren. Von der Schwierigkeit der Lichtsinnprüfung kann man sich nur durch Selbstbeobachtung einen Begriff machen. Der sich nach einem gewissen Dunkelaufenthalt bildende Lichtnebel, die Folge der chemischen Veränderungen in der Netzhaut, macht bei den ganz schwachen Lichtreizen ein präzises Urteil ziemlich schwierig, auch für geschulte Beobachter. Das Ergebnis der Prüfung hängt ab von der Intelligenz, der Aufmerksamkeit, dem guten Willen des Untersuchten und der Ausdauer des Arztes, weshalb es nicht gauz konstant ist. Bei Wiederholung der Prüfung sind die späteren Werte in der Regel höher als die ersten, eine Folge der Übung. Die Befunde eines Beobachters werden sich ohne weiteres miteinander vergleichen und zu Schlüssen benutzen lassen. 
Tabelle 1.

Der Lichtsinn von 100 Augenzitterern, geordnet nach dem Ergebnis der 1. Prüfung.

\begin{tabular}{|c|c|c|c|c|c|c|c|}
\hline 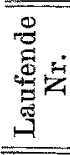 & 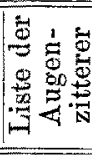 & 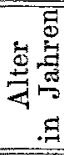 & 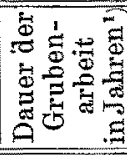 & $\begin{array}{l}\text { 1. Prüfung } \\
\text { R. E. }\end{array}$ & $\begin{array}{l}\text { 2. Prüfung } \\
\text { R. E. }\end{array}$ & $\begin{array}{l}\text { 3. Prüfung } \\
\text { R. F. }\end{array}$ & $\begin{array}{l}\text { 4. Prüfung } \\
\text { R. E. }\end{array}$ \\
\hline 1 & 307 & 53 & 31 & 50 & 400 & 1900 & 4700 \\
\hline 2 & 708 & 49 & 37 & 550 & 170 & 180 & 320 \\
\hline 3 & 570 & 34 & 17 & 780 & 5500 & 57000 & 91000 \\
\hline 4 & 604 & 40 & 24 & 850 & 430 & & \\
\hline 5 & 739 & 36 & 18 & 860 & & & \\
\hline 6 & 752 & 29 & 8 & 1250 & 5000 & 8400 & 11300 \\
\hline 7 & 533 & 43 & 25 & 2150 & 13850 & & \\
\hline 8 & 729 & 40 & 26 & 1667 & 3000 & 15600 & 22500 \\
\hline 9 & 723 & 44 & 30 & 2250 & 25000 & 33750 & \\
\hline 10 & 748 & 51 & 35 & 2800 & 12500 & & \\
\hline 11 & 481 & 42 & 25 & 3200 & 5000 & 12500 & 14400 \\
\hline 12 & 611 & 47 & 30 & 3400 & 1075 & & \\
\hline 13 & 757 & 29 & $?$ & 3600 & 4800 & 28571 & 30000 \\
\hline 14 & 276 & 48 & 24 & 4500 & 14600 & 8200 & \\
\hline 15 & 755 & 40 & 25 & 5000 & 6400 & & \\
\hline 16 & 681 & 51 & 35 & 5000 & & & \\
\hline 17 & 552 & 48 & 18 & 5000 & 8400 & 7250 & \\
\hline 18 & 678 & 36 & 13 & 5150 & 12300 & 10000 & \\
\hline 19 & 578 & 52 & 37 & 5400 & & & \\
\hline 20 & 719 & 49 & 33 & 5750 & 10900 & 14000 & \\
\hline 21 & 712 & 50 & 28 & 5900 & & & \\
\hline 22 & 735 & 45 & 31 & 6450 & & & \\
\hline 23 & 591 & 47 & 25 & 6500 & & & \\
\hline 24 & 214 & 38 & ? & 6600 & 10500 & & \\
\hline 25 & 698 & 43 & 27 & 6850 & 6750 & 13250 & \\
\hline 26 & 377 & 44 & 27 & 7000 & & & \\
\hline 27 & 692 & 49 & 32 & 7000 & & & \\
\hline 28 & 727 & 49 & 34 & 7500 & & & \\
\hline 29 & 705 & 41 & 26 & 9700 & 13800 & & \\
\hline 30 & 685 & 46 & 27 & 10000 & 14000 & 5300 & 13000 \\
\hline 31 & 680 & 34 & 21 & 10000 & 12500 & 17900 & 24250 \\
\hline 32 & 721 & 40 & 23 & 10000 & & & \\
\hline 33 & 36 & 33 & 17 & 10500 & 14200 & & \\
\hline 34 & 709 & 46 & 30 & 10500 & 29500 & & \\
\hline 35 & 758 & 52 & 32 & 10500 & & & \\
\hline 36 & 691 & 47 & 27 & 10750 & 7850 & & \\
\hline 37 & 736 & 42 & 17 & 11000 & & & \\
\hline 38 & 777 & 62 & 31 & 11700 & 10600 & & \\
\hline 39 & 694 & 39 & $?$ & 11800 & & & \\
\hline 40 & 436 & 41 & 23 & 11800 & 13300 & 25000 & 20000 \\
\hline 41 & 718 & 50 & 30 & 12000 & & & \\
\hline 42 & 715 & 46 & 17 & 12500 & & & \\
\hline 43 & 273 & 56 & 32 & 12700 & 19400 & 26000 & \\
\hline 44 & 728 & 45 & 25 & 13900 & & & \\
\hline 45 & 703 & 28 & 12 & 14200 & 25000 & 32200 & \\
\hline 46 & 682 & 49 & 23 & 14250 & 19400 & 26000 & \\
\hline 47 & 525 & 31. & 10 & 14300 & & & \\
\hline
\end{tabular}

1) Die Dauer der Grubenarbeit ist berechnet vom Beginn derselben bis zur ersten Lichtsinnprüfung. 
Beiträge zur Kenntnis des Augenzitterns der Bergleute.

\begin{tabular}{|c|c|c|c|c|c|c|c|}
\hline 总 & $\begin{array}{ll}5 \\
0 \\
0\end{array}$ & 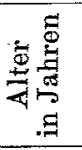 & 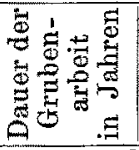 & $\begin{array}{l}\text { 1. Pruifung } \\
\text { R. E. }\end{array}$ & $\begin{array}{l}\text { 2. Prüfung } \\
\text { R. E. }\end{array}$ & $\begin{array}{l}\text { 3. Prüfung } \\
\text { R. E. }\end{array}$ & $\begin{array}{l}\text { 4. Prüfung } \\
\text { R. E. }\end{array}$ \\
\hline 48 & 337 & 50 & 31 & 15300 & & & \\
\hline 49 & 771 & 44 & 25 & 15800 & & & \\
\hline 50 & 724 & 44 & 20 & 17250 & & & \\
\hline 51 & 754 & 36 & 21 & 17250 & 13200 & & \\
\hline 52 & 126 & 46 & 30 & 17500 & 32600 & 15800 & \\
\hline 58 & 184 & 38 & 21 & 17500 & 20600 & 55000 & \\
\hline 54 & 756 & 47 & 32 & 17500 & 24000 & & \\
\hline 55 & 725 & 40 & 22 & 17850 & 23600 & & \\
\hline 56 & 741 & 30 & 14 & 18600 & 26780 & 25800 & \\
\hline 57 & 469 & 42 & 16 & 19000 & 20600 & & \\
\hline $5 s$ & 619 & 35 & 14 & 19000 & & & \\
\hline 59 & 720 & 46 & 32 & 19250 & & & \\
\hline 60 & 560 & 36 & 19 & 20000 & 34100 & & \\
\hline 61 & 33 & 41 & 18 & 20360 & 15500 & & \\
\hline 62 & 319 & 52 & 26 & 20400 & 20600 & & \\
\hline 63 & 714 & 46 & 22 & 20500 & 37000 & 51000 & \\
\hline 64 & 742 & 24 & 9 & 21111 & & & \\
\hline 65 & 369 & 36 & 21 & 21700 & 34400 & 40000 & \\
\hline 66 & 726 & 52 & 39 & 21900 & & & \\
\hline 67 & 538 & 34 & 18 & 23500 & 37500 & 66500 & \\
\hline 68 & 778 & 46 & 28 & 23900 & 11300 & 18800 & \\
\hline 69 & 745 & 40 & 17 & 24000 & 25750 & & \\
\hline 70 & 743 & 41 & 25 & 24200 & 15100 & & \\
\hline 71 & 716 & 49 & 26 & 24600 & 33150 & & \\
\hline 72 & 350 & 42 & 22 & 25000 & 26200 & & \\
\hline 73 & 81 & 40 & 21 & 25000 & 53000 & & \\
\hline 74 & 381 & 43 & 25 & 25200 & 26500 & & \\
\hline 75 & 707 & 24 & 8 & 26500 & & & \\
\hline 76 & 751 & 31 & 15 & 28250 & & & \\
\hline 77 & 512 & 36 & 16 & 28500 & 44000 & 38000 & \\
\hline 78 & 645 & 46 & 21 & 28500 & & & \\
\hline 79 & 711 & 34 & 10 & 29000 & & & \\
\hline 80 & 740 & 35 & 27 & 29000 & 19500 & 40000 & \\
\hline 81 & 625 & 46 & 25 & 30000 & 51000 & 28500 & 18300 \\
\hline 82 & 676 & 47 & 31 & 31400 & 33000 & 36300 & 54500 \\
\hline 83 & 226 & 35 & 18 & 31750 & & & \\
\hline 84 & 730 & 22 & 6 & 84300 & 37700 & 90300 & 71000 \\
\hline 85 & 762 & $26^{\circ}$ & 9 & 36000 & 35000 & & \\
\hline 86 & 737 & 54 & 38 & 36300 & & & \\
\hline 87 & 695 & 40 & 22 & 37400 & & & \\
\hline 88 & 373 & 39 & 20 & 38000 & 93340 & & \\
\hline 89 & 750 & 27 & 11 & 46000 & 50000 & & \\
\hline 90 & 779 & 51 & 36 & 44500 & & & \\
\hline 91 & 722 & 40 & 22 & 45000 & & & \\
\hline 92 & 746 & 31 & 15 & 46000 & 54000 & 65500 & \\
\hline 93 & 734 & 32 & 15 & 50000 & 61000 & & \\
\hline 94 & 713 & 33 & 16 & 51500 & 42500 & & \\
\hline 95 & 780 & 38 & 12 & 56000 & 46250 & & \\
\hline 96 & 679 & 32 & 13 & 58000 & 41600 & 50000 & \\
\hline 97 & 358 & 32 & 15 & 60000 & & & \\
\hline 98 & 653 & 40 & 25 & 82000 & 48000 & & \\
\hline 99 & 738 & 32 & 14 & 82500 & & & \\
\hline 100 & 744 & 50 & 31 & 103000 & 86000 & 91000 & \\
\hline
\end{tabular}


Durchschnittswert des Lichtsinns nach einstündigem Dunkelaufenthalt.

I. Probe 100 Fälle 20506 relative Empfindlichkeitswerte,

II. $" 65 \quad$ " $24623 \quad " \quad$,

III. $" 34 \quad " 30897 \quad " \quad$,

IV. $" 13 \quad, 28866 \quad " \quad$ "

Der Durchschnitt aller 212 Proben ergab 23947 R. E. Der niedrigste Wert betrug 50 (Fall 307. Fig. 2), der höchste 103000 (Fig. 6)

\section{Lichtsinn}

R.E.

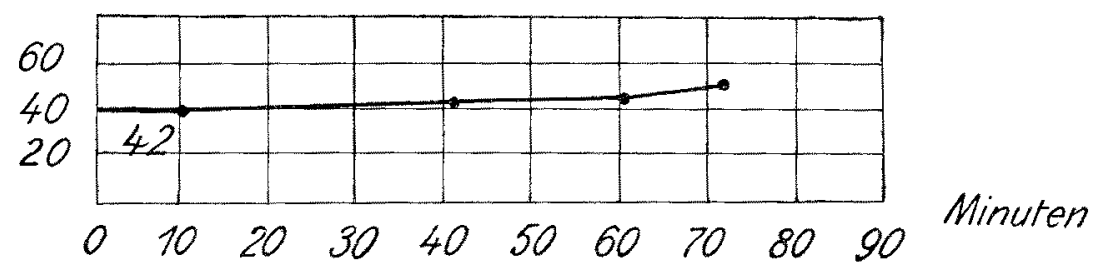

Fig. 2. Fall 307. 1. Probe.

\section{Lichrsinn}

R.E

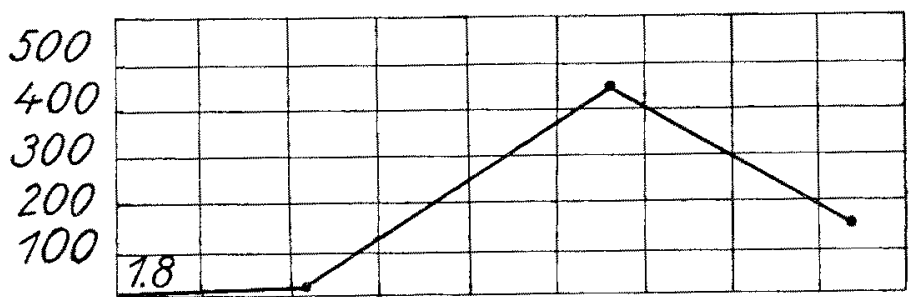

$0 \quad 1020 \quad 30 \quad 40 \quad 50 \quad 60 \quad 70 \quad 80 \quad 90$ Minuten

Fig. 3. Fall 307. 2. Probe.

\section{Lichtsinn}

R. E.

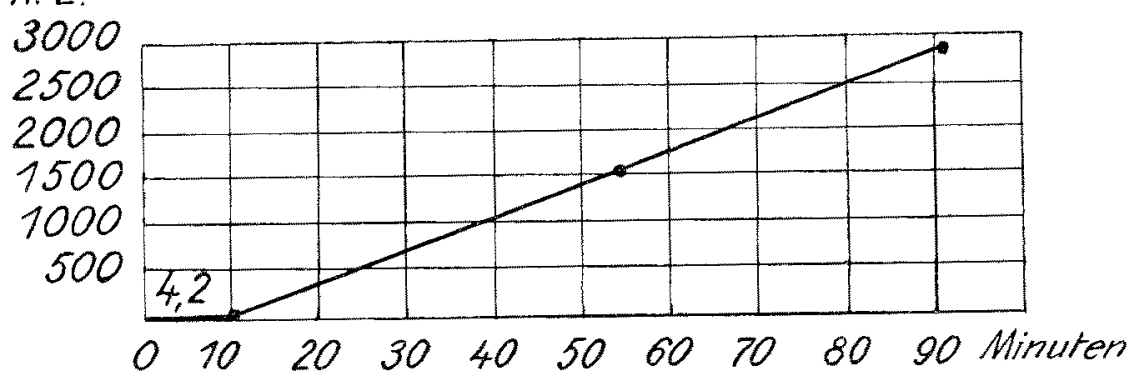

Fig. 4. Fall 307. 3. Probe. 
Beiträge zur Kenntnis des Augenzitterns der Bergleute.

relative Empfindlichkeitswerte. Die Zahl im Scheitelpunkt gibt die Anfangsschwelle an. Manchmal steigt die Kurve in gerader Linie, Lichtsinn

R.E.

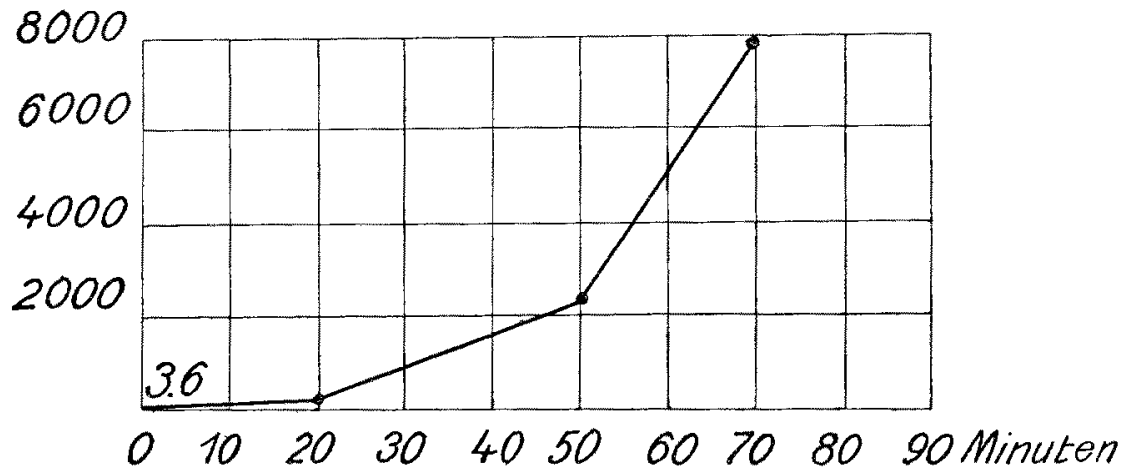

Fig. 5. Fall 307. 4. Probe.

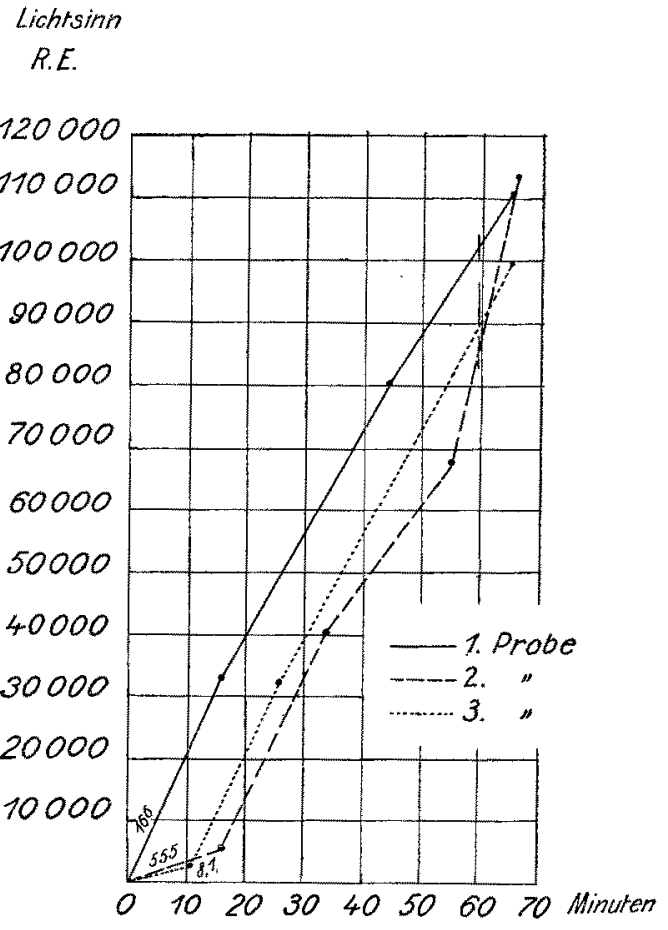

Fig. 6.

manchmal mit Stufen auf ihre endgültige Höhe. Einzelne Kurven weisen auch starke Remissionen auf. (Aufmerksamkeitsschwankungen?)

Das Ergebnis wiederholter Prüfungen ist selten ganz beständig. 
In der Regel wird bei späterer Untersuchung ein höherer Wert erreicht, was wohl als Folge der Übung anzusehen ist, wenn sich die Unterschiede in mässigen Grenzen halten. Fiur so gewaltige Verschiedenheiten wie bei Nr. 3 (570) (Fig. 7) fehlt mir die Erklärung. $18 \mathrm{mal}$

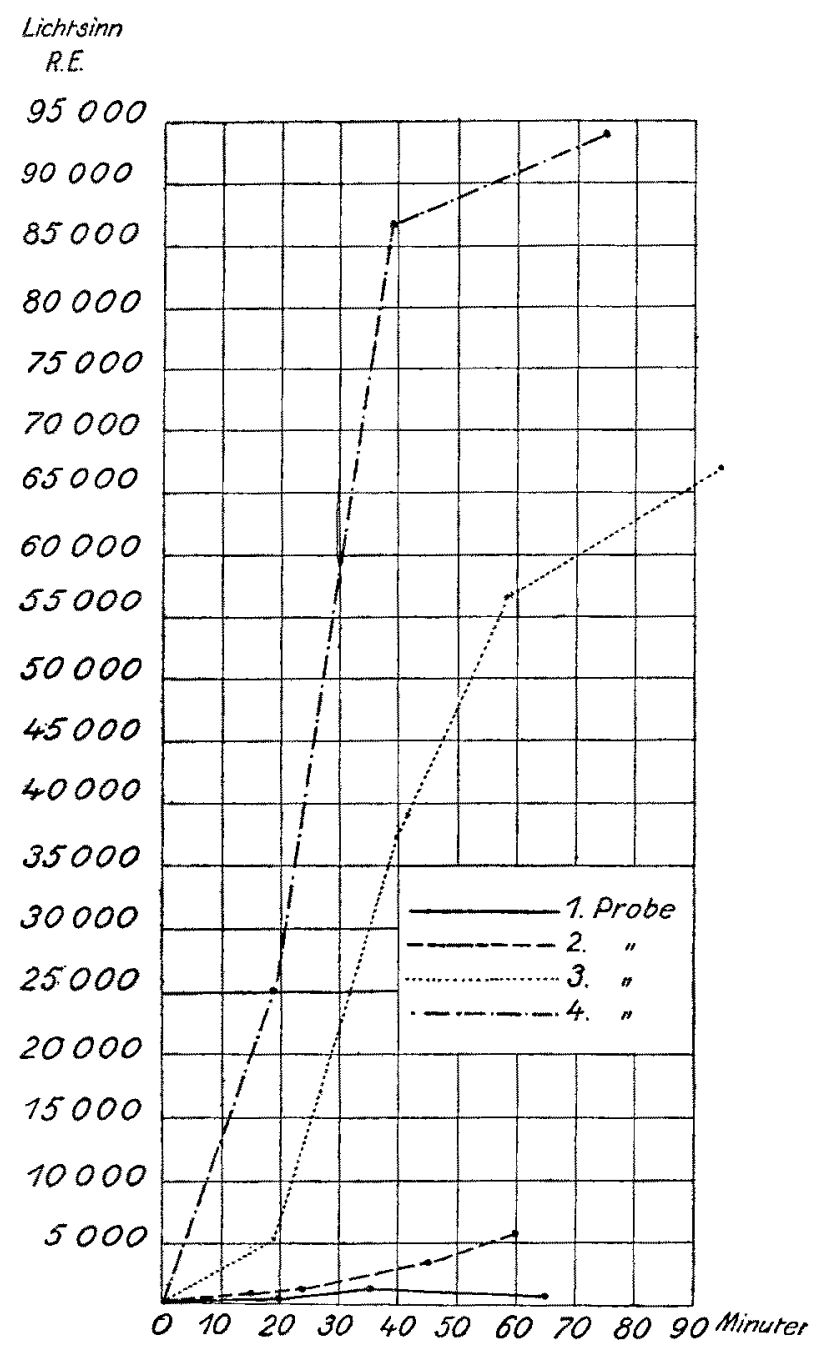

Fig. 7.

ergab nicht die erste, sondern eine spätere Probe den niedrigsten Lichtsinnwert. Der erste Eindruck obiger Statistik ist der, dass der Lichtsinn der Augenzitterer sich weit unter der normalen Höhe hält, der nach etwa 45 Minuten bereits bei 250000 R. E. liegen soll. Ich muss allerdings gestehen, dass es mir bis jetzt, auch bei Gesunden, nie ge- 
lungen ist, letzteren Wert zu erreichen. 63 Augenzitterer blieben bei der ersten Probe unter dem Durchschnitt (20506). Wie erklärt sich dieser niedrige Lichtsinn?

Manche Forscher haben eine Abstumpfung des Lichtsinns im Laufe der Grubenarbeit infolge des plötzlichen Wechsels von tiefer Dunkelheit und Tageshelle angenommen, was aber schwer verständlich ist. Näher liegt es, die grossen Unterschiede im Lichtsinn für angeboren zu halten. Um das festzustellen, untersuchte ich Jünglinge unter 16 Jahren, die noch nicht zur Grubenarbeit zugelassen werden, und andere, die weniger als 3 Jahre unter Tage arbeiten, also noch nicht von Augenzittern befallen werden konnten.

Tabelle 2.

Der Lichtsinn jugendlicher Arbeiter ohne Augenzittern.

\begin{tabular}{c|c|c|c|c}
\hline Nr. & $\begin{array}{c}\text { Alter } \\
\text { in Jahren }\end{array}$ & $\begin{array}{c}\text { Dauer } \\
\text { der Grubenarbeit }\end{array}$ & Lichtsinn & $\begin{array}{c}\text { Grösse } \\
\text { in cm }\end{array}$ \\
\hline 1 & 15 & über Tage & 10526 & 155,5 \\
2 & 15 & " & 21000 & 146,1 \\
3 & 15 & & 46000 & $?$ \\
4 & 15 & & 65000 & 155,7 \\
5 & 15 & & 66667 & 149 \\
6 & 15 & & 78000 & 166,3 \\
7 & 17 & & 24000 & 138,5 \\
8 & 17 & 5 Monate & 52000 & 159 \\
9 & 17 & 9 & 55000 & 159 \\
10 & 17 & 12 & 55000 & 169 \\
11 & 18 & 18 & 11800 & 168 \\
12 & 18 & 4 & 14250 & 163 \\
13 & 19 & 8 & 10150 & 171 \\
14 & 19 & 8 & 38000 & 175,5 \\
15 & 20 & $5 \%$ & 33000 & 166 \\
16 & 21 & 12 & 50000 & 169,5 \\
17 & 22 & 6 & 93500 & 168 \\
18 & 22 & 6 & 73000 & 163 \\
19 & 32 & 2 & 67500 & 175,3 \\
& & & &
\end{tabular}

Aus dieser Statistik geht hervor, dass der Lichtsinn bei jugendlichen Arbeitern, die den Schädlichkeiten der Grubenarbeit noch nicht oder erst kurze Zeit ausgesetzt sind, von sehr verschiedener Schärfe ist. Es muss sich also um angeborene Unterschiede handeln. Bei allen waren die Augen, abgesehen von einzelnen geringen Refraktionsfehlern, normal und von guter Sehkraft.

Bemerkenswert ist, dass Nr. 11, der einen sehr niedrigen Lichtsinn hat und bereits über schlechtes Sehen in der Grube klagt, besonders wenn er mittags einfährt, der Sohn eines Augenzitterers ist. 
Letzterer (787), jetzt 48 Jahre alt, leidet seit 15 Jahren an Augenzittern; hochgradige Übersichtigkeit; Grösse 170,2; Lichtsinn 5750 R. E, ; Zittern lebhaft, R. horizontal, L. schräg.

Ferner scheint ein schädlicher

\section{Einfluss des Alkohols auf den Lichtsinn}

zu bestehen. Abgesehen von Horn (123) ist darïber meines Wissens nichts veröffentlicht worden. Folgende Tabelle enthält 14 Fälle von Augenzittern bei Alkoholikern. Sie ist klein, aber in bezug auf die Diagnose des Alkoholmissbrauches, die ja oft schwer zu präzisieren ist, ziemlich sicher. Die Fälle 2, 4, 6 (Fig. 2-5), 8, 10, 11, 12, 13 sind starke Trinker, was festgestellt ist durch Mitteilung der Verwandten, der Knappschaftsältesten oder meine eigenen Beobachtungen. Fall 1, der jüngste, gab an, täglich 1-2 Flaschen Bier und Sonntags einen Schnaps zu trinken. Bei 3, 5, 7, 9, 14 habe ich gelegentlich öfterer Konsultationen stärkeren Alkoholgenuss an seiner Wirkung auf das Augenzittern, worüber später die Rede sein wird, beobachtet. Bei Nr. 8 ist das rechte Auge geschrumpft. Er gehört zu den wenigen Fällen von Einäugigkeit mit Augenzittern, die ich gesehen habe. Beide

Tabelle 3.

Lichtsinn and Grosse bei Alkoholikern mit Augenzittern.

\begin{tabular}{r|c|c|c|c|c}
\hline Nr. & Listen-Nr. & $\begin{array}{c}\text { Alter } \\
\text { in Jahren }\end{array}$ & $\begin{array}{c}\text { Dauer der } \\
\text { Grubenarbeit } \\
\text { in Jahren }\end{array}$ & $\begin{array}{c}\text { Lichtsinn } \\
\text { R. E. }\end{array}$ & $\begin{array}{c}\text { Grösse } \\
\text { in cm }\end{array}$ \\
\hline \hline 1 & 757 & 29 & $?$ & 3600 & 161,3 \\
2 & 214 & 38 & $?$ & 6600 & 157 \\
3 & 436 & 41 & $?$ & 11800 & 183 \\
4 & 736 & 42 & 17 & 11000 & 162,3 \\
5 & 205 & 43 & $?$ & 7900 & $?$ \\
6 & 307 & 53 & 31 & $50 !$ & 168 \\
7 & 585 & 45 & 29 & 19800 & 157,5 \\
8 & 591 & 47 & 25 & 6500 & 166,5 \\
9 & 250 & 48 & 26 & 19200 & 163,5 \\
10 & 719 & 49 & 33 & 5750 & 161 \\
11 & 727 & 49 & 34 & 7500 & 153,5 \\
12 & 299 & 49 & 31 & 26200 & 165,3 \\
13 & 337 & 50 & 31 & 15300 & $\mathbf{1 6 8}$ \\
14 & 726 & 52 & 39 & 21900 & $\mathbf{1}$ \\
& & & & &
\end{tabular}

Augen zittern heftig. Alle übrigen haben, abgesehen von eimigen mässigen Refraktionsfehlern, normale Augen.

Der Lichtsinn dieser Fälle ist teilweise ausserordentlich schlecht, z. B. bei 6 (Fig. 2-5). Der Durchschnittswert beträgt nur 11292 R.E., also kaum die Hälfte des Gesamtdurchschnitts (20506). Nur zwei (12 und 14) übertreffen ihn. 
Der Beachtung empfehle ich noch die Grösse dieser Leute. Die meisten sind klein. Nur zwei (3 und 14) haben mehr als Durchschnittsgrösse $(168,3)$.

Tabelle 4.

Beziehungen zwischen Alter, Grösse und Lichtsinn bei Augenzitterem geordnet nach dem Alter.

\begin{tabular}{c|c|c|c|c|c|c}
\hline \hline Periode & $\begin{array}{c}\text { Lau- } \\
\text { fende } \\
\text { in Jahren }\end{array}$ & Listen-Nr. & $\begin{array}{c}\text { Alter } \\
\text { in Jahren }\end{array}$ & $\begin{array}{c}\text { Grösse } \\
\text { in cm }\end{array}$ & $\begin{array}{c}\text { 1. Lichtsinn } \\
\text { R. E. }\end{array}$ & $\begin{array}{c}\text { Durchschnitt } \\
\text { R. E. }\end{array}$ \\
\hline
\end{tabular}

$20-24$

$\mid \begin{aligned} & 1 \\ & 2 \\ & 3\end{aligned}$

742
730
707

$25-29$

\begin{tabular}{|l|l|}
1 & 762 \\
2 & 708 \\
3 & 757 \\
4 & 752 \\
5 & 750 \\
\hline
\end{tabular}

$30-34$

\begin{tabular}{|r|r|}
1 & 734 \\
2 & 525 \\
3 & 751 \\
4 & 738 \\
5 & 538 \\
6 & 711 \\
7 & 570 \\
8 & 680 \\
9 & 679 \\
10 & 36 \\
11 & 746 \\
12 & 358 \\
13 & 741 \\
14 & 713
\end{tabular}

$35-39$

\begin{tabular}{|r|r|}
1 & 678 \\
2 & 694 \\
3 & 214 \\
4 & 740 \\
5 & 369 \\
6 & 184 \\
7 & 619 \\
8 & 780 \\
9 & 226 \\
10 & 739 \\
11 & 754 \\
12 & 560 \\
13 & 512 \\
14 & 373
\end{tabular}

\section{Gruppe I.}

$\left.\begin{array}{l|l|l|l|}24 & 163 & 21111 & \\ 22 & 165,5 & 34300 & \\ 24 & 165,5 & 26500 & \end{array}\right\} 27303$

Gruppe II.

\begin{tabular}{l|l}
26 & 158,1 \\
28 & 160,5 \\
29 & 161,3 \\
29 & 166,5 \\
27 & 168
\end{tabular}

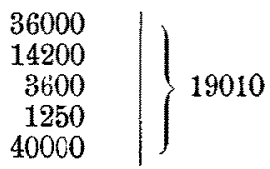

Gruppe III.

31

31

32

34

34

34

34

32

33

31

32

30

33

\begin{tabular}{|l|}
154 \\
165,3 \\
165,5 \\
166 \\
167 \\
167,5 \\
168 \\
168 \\
171 \\
171 \\
174 \\
174,3 \\
175,1 \\
176
\end{tabular}

50000

14300

28250

82500

23500

29000

780

10000

58000

10500

46000

60000

18600

51500

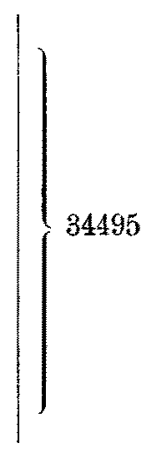

Gruppe IV.
5150
11800
6600
29000
21700
17500
19000
56000
31750
860
17250
20000
28500
38000

$\left.\begin{array}{l|l|r|}36 & 156 & 5150 \\ 39 & 156 & 11800 \\ 38 & 157 & 6600 \\ 35 & 159,7 & 29000 \\ 36 & 167,5 & 21700 \\ 38 & 168 & 17500 \\ 35 & 169 & 19000 \\ 38 & 174 & 56000 \\ 35 & 179 & 31750 \\ 36 & 174,3 & 860 \\ 36 & 175,8 & 17250 \\ 36 & 177 & 20000 \\ 36 & 177 & 28500 \\ 39 & 177 & 38000\end{array}\right\}$

.

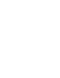

ב 


\begin{tabular}{|c|c|c|c|c|c|c|}
\hline $\begin{array}{l}\text { Periode } \\
\text { in Jahren }\end{array}$ & $\begin{array}{l}\text { Lau- } \\
\text { fende } \\
\mathrm{Nr} .\end{array}$ & Listen-Nr. & $\begin{array}{c}\text { Alter } \\
\text { in Jahren }\end{array}$ & $\begin{array}{l}\text { Grösse } \\
\text { in } \mathrm{cm}\end{array}$ & $\begin{array}{l}\text { 1. Lichtsinn } \\
\text { R. E. }\end{array}$ & $\begin{array}{l}\text { Durehsehnitt } \\
\text { R. E. }\end{array}$ \\
\hline
\end{tabular}

Gruppe $V$.

$40-44$

\begin{tabular}{|r|r|}
1 & 724 \\
2 & 723 \\
3 & 725 \\
4 & 698 \\
5 & 736 \\
6 & 743 \\
7 & 481 \\
8 & 377 \\
9 & 350 \\
10 & 771 \\
11 & 604 \\
12 & 381 \\
13 & 81 \\
14 & 469 \\
15 & 533 \\
16 & 722 \\
17 & 729 \\
18 & 705 \\
19 & 33 \\
20 & 721 \\
21 & 755 \\
22 & 695 \\
23 & 653 \\
24 & 436 \\
\hline
\end{tabular}

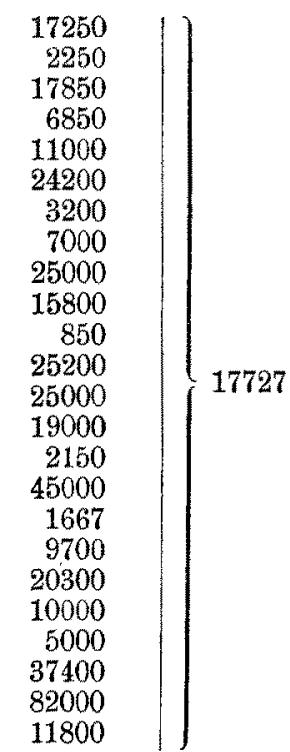

Gruppe VI.

$\left.\begin{array}{r|r|l|l|l|r|}45-49 & 1 & 727 & 49 & 153,5 & 7500 \\ & 2 & 756 & 47 & 154 & 17500 \\ 3 & 692 & 49 & 161 & 7000 \\ & 4 & 719 & 49 & 161 & 5750 \\ 5 & 709 & 46 & 162 & 10500 \\ 6 & 735 & 45 & 162,5 & 6450 \\ 7 & 682 & 49 & 163,5 & 14250 \\ 8 & 611 & 47 & 165 & 3400 \\ 9 & 276 & 48 & 166,25 & 4500 \\ 10 & 720 & 46 & 166,25 & 19200 \\ 11 & 591 & 47 & 166,5 & 6500 \\ 12 & 691 & 47 & 169 & 10750 \\ 13 & 645 & 46 & 169 & 28500 \\ 14 & 625 & 46 & 169 & 30000 \\ 15 & 552 & 48 & 170 & 5000 \\ 16 & 714 & 46 & 170,5 & 20500 \\ 17 & 745 & 40 & 170,5 & 24000 \\ 18 & 728 & 45 & 171 & 13900 \\ 19 & 778 & 46 & 172 & 23900 \\ 20 & 676 & 47 & 172 & 31400 \\ 21 & 716 & 49 & 172 & 24600 \\ 22 & 715 & 46 & 172,25 & 12500 \\ 23 & 685 & 46 & 173 & 10000 \\ 24 & 708 & 49 & 174,5 & 550 \\ 25 & 126 & 46 & 182 & 17500\end{array}\right\}\left.\right|_{14228}$


Beiträge zur Kenntnis des Augenzitterns der Bergleute.

\begin{tabular}{|c|c|c|c|c|c|c|}
\hline $\begin{array}{l}\text { Periode } \\
\text { in Jahren }\end{array}$ & $\begin{array}{c}\text { Lau- } \\
\text { fende } \\
\text { Nr. }\end{array}$ & Listen-Nr & $\begin{array}{c}\text { Alter } \\
\text { in Jahren }\end{array}$ & $\begin{array}{l}\text { Grösse } \\
\text { in } \mathrm{cm}\end{array}$ & $\begin{array}{l}\text { 1. Lichtsinn } \\
\text { R. E. }\end{array}$ & $\begin{array}{l}\text { Durchschnitt } \\
\text { R. E. }\end{array}$ \\
\hline \multicolumn{7}{|c|}{ Gruppe VII. } \\
\hline $50-54$ & $\begin{array}{r}1 \\
2 \\
3 \\
4 \\
5 \\
6 \\
7 \\
8 \\
9 \\
10 \\
11 \\
12 \\
13\end{array}$ & $\begin{array}{l}758 \\
712 \\
718 \\
681 \\
737 \\
578 \\
748 \\
307 \\
337 \\
779 \\
726 \\
319 \\
744\end{array}$ & $\begin{array}{l}52 \\
50 \\
50 \\
51 \\
54 \\
52 \\
51 \\
53 \\
50 \\
51 \\
52 \\
52 \\
50\end{array}$ & $\begin{array}{l}160,1 \\
161 \\
163,6 \\
164 \\
164 \\
165,2 \\
166 \\
168 \\
168 \\
168 \\
168,5 \\
172 \\
172\end{array}$ & $\begin{array}{r}10500 \\
5900 \\
12000 \\
5000 \\
36300 \\
5400 \\
2800 \\
50 \\
15300 \\
44500 \\
21900 \\
20400 \\
103000\end{array}$ & 21773 \\
\hline \multicolumn{7}{|c|}{ Gruppe VIII. } \\
\hline $55-59$ & 1 & 273 & 56 & $\mathbf{1 6 9 , 7 5}$ & 12700 & 12700 \\
\hline \multicolumn{7}{|c|}{ Gruppe IX. } \\
\hline $60-64$ & 1 & 777 & 62 & 172 & 11700 & 11700 \\
\hline
\end{tabular}

Die 100 Fälle der 1. Tabelle sind in der 4. Tabelle nach 5 jährigen Perioden geordnet, und in jeder Periode ist die Reihenfolge nach der Grösse bestimmt. Der Lichtsinndurchsehnitt zeigt mit steigendem Alter von der III. Gruppe an bis zum Schluss ein allmähliches Sinken, wobei nur die Gruppe VII aus dem Rahmen herausspringt. Die Gruppe I und besonders II haben auffallend niedrigen Lichtsinn.

Ein kurzer Vergleich der Fälle in jeder Gruppe lehrt, dass sich niedriger Lichtsinn mehr bei kleinen als bei grossen. Leuten findet, weshalb alle Fälle nochmals nach der Grösse geordnet wurden (Tab. 5).

Tabelle 5.

Beziehungen zwischen Lichtsinn und Grösse bei Augenzitterern geordnet nach der Grösse.

\begin{tabular}{|c|c|c|c|c|c|c|}
\hline & $\begin{array}{c}\text { Lau- } \\
\text { fende } \\
\text { Nr. }\end{array}$ & Listen-Nr. & $\begin{array}{c}\text { Alter } \\
\text { in Jahren }\end{array}$ & $\begin{array}{l}\text { Grösse } \\
\text { in } \mathrm{cm}\end{array}$ & $\begin{array}{l}\text { Lichtsinn } \\
\text { R. E. }\end{array}$ & $\begin{array}{l}\text { Durchschni } \\
\text { R. E. }\end{array}$ \\
\hline \multicolumn{7}{|c|}{ Gruppe I. } \\
\hline $151-155 \mathrm{~cm}$ & $\begin{array}{l}1 \\
2 \\
3\end{array}$ & $\begin{array}{l}727 \\
756 \\
743\end{array}$ & $\begin{array}{l}49 \\
47 \\
32\end{array}$ & $\begin{array}{l}153,5 \\
154 \\
154\end{array}$ & $\begin{array}{r}7500 \\
17500 \\
50000\end{array}$ & 25000 \\
\hline \multicolumn{7}{|c|}{ Gruppe II. } \\
\hline $155-160 \mathrm{~cm}$ & $\begin{array}{r}4 \\
5 \\
6 \\
7 \\
8 \\
9 \\
10 \\
11\end{array}$ & $\begin{array}{l}678 \\
694 \\
214 \\
762 \\
724 \\
723 \\
725 \\
740\end{array}$ & $\begin{array}{l}36 \\
39 \\
38 \\
26 \\
44 \\
44 \\
40 \\
35\end{array}$ & $\begin{array}{l}156 \\
156 \\
157 \\
158,1 \\
158,2 \\
158,5 \\
159,3 \\
159,7\end{array}$ & $\begin{array}{r}5150 \\
11800 \\
6600 \\
36000 \\
17250 \\
2250 \\
17850 \\
29000\end{array}$ & 15737 \\
\hline
\end{tabular}

จ. Graefe's Archiv für Ophthaimologie $\mathrm{LXXXIX,} 3$. 


\begin{tabular}{|c|c|c|c|c|c|c|}
\hline & $\begin{array}{l}\text { Lau- } \\
\text { fende } \\
\text { Nr. }\end{array}$ & Listen-Nr. & $\begin{array}{c}\text { Alter } \\
\text { in Jahren }\end{array}$ & $\begin{array}{l}\text { Grösse } \\
\text { in cm }\end{array}$ & $\begin{array}{c}\text { Lichtsinn } \\
\text { R. E. }\end{array}$ & $\begin{array}{l}\text { Durchschnitt } \\
\text { R. E. }\end{array}$ \\
\hline \multicolumn{7}{|c|}{ Gruppe III. } \\
\hline \multirow[t]{20}{*}{$160-165 \mathrm{~cm}$} & 12 & 758 & $52^{k}$ & 160,1 & 10500 & \multirow{20}{*}{11660,5} \\
\hline & 13 & 703 & 28 & 160,5 & 14200 & \\
\hline & 14 & 719 & 49 & 161 & 5750 & \\
\hline & 15 & 712 & 50 & 161 & 5900 & \\
\hline & 16 & 698 & 43 & 161 & 6850 & \\
\hline & 17 & 692 & 49 & 161 & 7000 & \\
\hline & 18 & 757 & 29 & 161,3 & 3600 & \\
\hline & 19 & 709 & 46 & 162 & 10500 & \\
\hline & 20 & 736 & 42 & 162,3 & 11000 & \\
\hline & 21 & 735 & 45 & 162,5 & 6450 & \\
\hline & 22 & 742 & 24 & 163 & 21111 & \\
\hline & 23 & 743 & 41 & 163 & 24200 & \\
\hline & 24 & 682 & 49 & 163,5 & 14250 & \\
\hline & 25 & 718 & 50 & 163,6 & 12000 & \\
\hline & 26 & 481 & 42 & 164 & 3200 & \\
\hline & 27 & 681 & 51 & 164. & 5000 & \\
\hline & 28 & 377 & 44 & 164 & 7000 & \\
\hline & 29 & 737 & 54 & 164 & 36300 & \\
\hline & 30 & 350 & 42 & 164,5 & 25000 & \\
\hline & 31 & 611 & 47 & 165 & 3400 & \\
\hline \multicolumn{7}{|c|}{ Gruppe IV. } \\
\hline $165-170 \mathrm{~cm}$ & 32 & 578 & 52 & 165,2 & 5400 & \multirow{34}{*}{18933} \\
\hline & 33 & 771 & 44 & 165,2 & 15800 & \\
\hline & 34 & 525 & 31 & 165,3 & 14300 & \\
\hline & 35 & 707 & 24 & 165,5 & 26500 & \\
\hline & 36 & 751 & 31 & 165,5 & 28250 & \\
\hline & 37 & 780 & 22 & 165,5 & 34300 & \\
\hline & 38 & 748 & 51 & 166 & 2800 & \\
\hline & 39 & 738 & 32 & 166 & 82500 & \\
\hline & 40 & 276 & 48 & 166,25 & 4500 & \\
\hline & 41 & 720 & 46 & 166,25 & 19250 & \\
\hline & 42 & 604 & 40 & 166,5 & 850 & \\
\hline & 43 & 752 & 29 & 166,5 & 1250 & \\
\hline & 44 & 591 & 47 & 166,5 & 6500 & \\
\hline & 45 & 381 & 43 & 166,5 & 25200 & \\
\hline & 46 & 538 & 34 & 167 & 23500 & \\
\hline & 47 & 369 & 36 & 167,5 & 21700 & \\
\hline & 48 & 711 & 34 & 167,5 & 29000 & \\
\hline & 49 & 307 & 53 & 168 & 50 & \\
\hline & 50 & 570 & 34 & 168 & 780 & \\
\hline & 51 & 680 & 34 & 168 & 10000 & \\
\hline & 52 & 397 & 50 & 168 & 15300 & \\
\hline & 53 & 184 & 38 & 168 & 17500 & \\
\hline & 54 & 81 & 40 & 168 & 25000 & \\
\hline & 55 & 750 & 27 & 168 & 40000 & \\
\hline & 56 & 779 & 51 & 168 & 44500 & \\
\hline & 57 & 726 & 52 & 168,5 & 21900 & \\
\hline & 58 & 691 & 47 & 169 & 10750 & \\
\hline & 59 & 619 & 35 & 169 & 19000 & \\
\hline & 60 & 469 & 42 & 169 & 19000 & \\
\hline & 61 & 645 & 46 & 169 & 28500 & \\
\hline & 62 & 625 & 46 & 169 & 30000 & \\
\hline & 63 & 533 & 43 & 169,5 & 2150 & \\
\hline & 64 & 273 & 56 & 169,75 & 12700 & \\
\hline & 65 & 552 & 48 & $170^{\prime}$ & 5000 & \\
\hline
\end{tabular}




\begin{tabular}{l|c|c|c|c|c}
\hline \hline & $\begin{array}{c}\text { Lau- } \\
\text { fende } \\
\text { Nr. Listen-Nr. }\end{array}$ & $\begin{array}{c}\text { Alter } \\
\text { in Jahren }\end{array}$ & $\begin{array}{c}\text { Grösse } \\
\text { in cm }\end{array}$ & $\begin{array}{c}\text { Lichtsinn } \\
\text { R. E. }\end{array}$ & $\begin{array}{c}\text { Durchschnitt } \\
\text { R. E. }\end{array}$ \\
\hline
\end{tabular}

$170-175 \mathrm{~cm}$

\begin{tabular}{l|r}
66 & 722 \\
67 & 729 \\
68 & 714 \\
69 & 745 \\
70 & 705 \\
71 & 36 \\
72 & 728 \\
73 & 33 \\
74 & 679 \\
75 & 721 \\
76 & 777 \\
77 & 319 \\
78 & 778 \\
79 & 716 \\
80 & 676 \\
81 & 744 \\
82 & 715 \\
83 & 685 \\
84 & 226 \\
85 & 746 \\
86 & 780 \\
87 & 358 \\
88 & 708 \\
89 & 739 \\
90 & 755
\end{tabular}

\section{Gruppe V.}

40

46

40

41

33

45

41

32

40

62

52

46

49

47

50

46

\section{6}

35

31

38

32

49

36

40

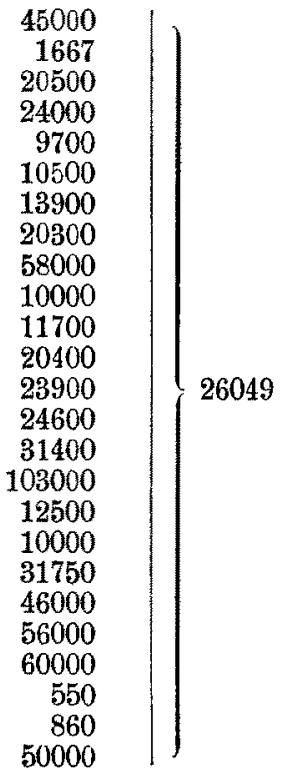

Gruppe VI.

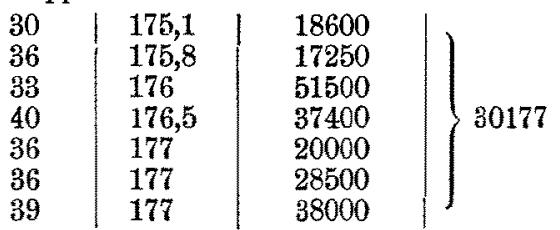

Gruppe VII.

\begin{tabular}{r|r|r|l|l|l|l|}
$180-185 \mathrm{~cm}$ & 98 & 653 & 40 & 181,5 & 82000 & 17500 \\
& 99 & $\mathbf{1 2 6}$ & 46 & 182 & 1837100 \\
& 100 & 436 & 41 & 183 & 11800 & \}
\end{tabular}

In der Tabelle 5 steigt der Lichtsinn von der III. Gruppe regelmässig an. Der Lichtsinnwert der Leute von $180-185 \mathrm{~cm}$ ist über dreimal so gross, als bei Leuten von $160-165 \mathrm{~cm}$. Die beiden ersten Gruppen passen wiedor nicht vollständig in das andere Schema. Dass der Lichtsinn an sich mit der Körpergrösse etwas zu tun hat, ist natürlich ausgeschlossen.

Das Ergebnis obiger Untersuchungen scheint aber zu sein, dass verschiedene Faktoren bei der Entstehung des Augenzitterns mitwirken, zuerst der Lichtsinn, dann die Grösse. Je schlechter der Lichtsinn, 
und je grösser der Körper, desto grösser die Gefahr des Augenzitterns. Hoher Lichtsinn und kleine Gestalt bieten einen relativen Schutz, unter sonst gleichen Umständen.

\section{Befund bei Steigern.}

Nach der Ansicht aller Autoren ist die Augenzitterngefahr für die einzelnen Klassen der Grubenarbeiter verschieden gross. Am grössten ist sie für die Hauer, geringer für die Reparatur- und Zimmerhauer, noch geringer für Schlepper und Steiger. Wenn also z. B. letztere weniger unter der Einwirkung der äusseren Ursachen des Augenzitterns (Arbeitsbedingungen) stehen und trotzdem von Augenzittern befallen werden, so darf man erwarten, dass bei ihnen die inneren Ursachen (Veranlagung) mehr hervortreten werden, als bei dem Durchschnitt der Hauer. Ich gebe unter diesem Gesichtspunkt den Befund vou 4 Steigern (Tab. 6).

Tabelle 6.

\begin{tabular}{c|c|c|c|c|c}
\hline Nr. & $\begin{array}{c}\text { Nystagmus- } \\
\text { liste }\end{array}$ & $\begin{array}{c}\text { Alter } \\
\text { in Jahren }\end{array}$ & $\begin{array}{c}\text { Dauer der } \\
\text { Grubenarbeit } \\
\text { in Jahren }\end{array}$ & $\begin{array}{c}\text { Grösse } \\
\text { in cm }\end{array}$ & $\begin{array}{c}\text { Lichtsinn } \\
\text { R. E. }\end{array}$ \\
\hline 1 & 36 & 33 & 17 & 171 & 10500 \\
2 & 791 & 34 & 16 & 172 & 9000 \\
3 & 721 & 40 & 23 & 172 & 10000 \\
4 & 126 & 46 & 30 & 182 & 17500
\end{tabular}

1. (36) 4. VIII. 1911. Bis 1906 vor der Kohle. Seitdem Steiger. Seit Lichrsinn

R.E.

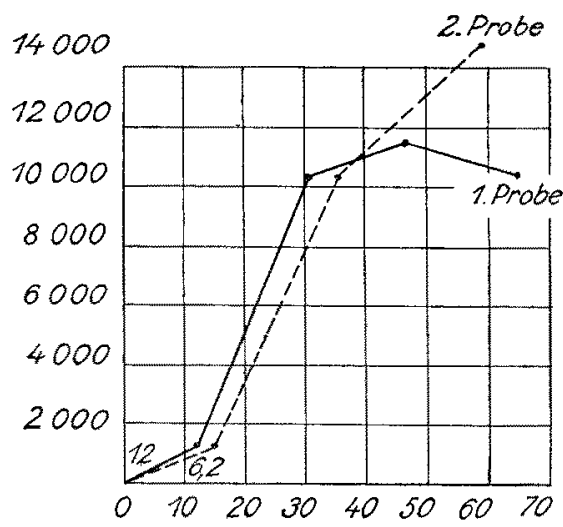

Fig. 8. einem Jahr will er an Augenzittern leiden. Befund negativ. R. and L. $-4 D=4 / 4$. Mit Maddox auf $50 \mathrm{~cm} 3^{1} / 2_{2}^{\circ}$, anf $30 \mathrm{~cm} 5^{0}$ Diverg., keine Höhenablenkung. Adaptationskurve Fig. 8.

18. I. 1912. Klagt wieder über Springen der Lichter, wenn er in gebückter Haltung durch den Quersehlag geht. Jetzt ist mit dem Augenspiegel Zittern zu finden, aber nur zeitweise bei starker Blickhebung, und ganz leise, kaum eine Venenbreite, vertikal, R. $>$ L. Bis 27. VI.

1914 immer in der Grube. Zittern ganz gering, vertikal. 
2. (791) Bis 1910 vor der Kohle; dann Steiger. Augenzittern seit 2-3 Monaten. Rechtes Auge immer sehwach.

13. X. 1914. R. Finger: $4 \mathrm{~m} ;-1,25 \mathrm{D}=$ $\left.{ }^{4}\right|_{36} ; \mathrm{L} .=\left.4\right|_{11} ;-1,5 \mathrm{D}$ $=4 / 5$. Heftiges Zittern bei tiefer Senkung des Blickes, R. rotierend mit Uhrzeiger, L. Raddrehung. Adaptationskurve siehe Fig. 9.

3. (72) 23 Jahre in der Grube, 2 Jahre Schlepper, 7 Jahre Hauer, dann Steiger. Das Augenzittern begann in der Lehrhauerzeit, wurde in der Hauer-

\section{Lichrsinn}

R.E.

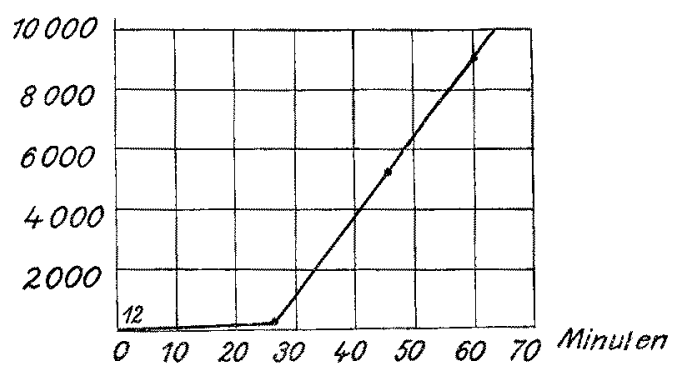

Fig. 9. zeit schlimmer, in der Steigerzeit wieder besser.

12. III. 1914. R. u. L. $+0,5=4 / 4.2$ u. $\left.3^{1}\right|_{2} ^{0}$ Diverg. R. $1 / 4^{0}$ höher.

Zittern schwer zu sehen. Nach Bücken gelingt es, zuerst links, dann auch rechts Zittern nachzuweisen; vertikal; Amplitude L. $>$ R.

4. (126) Seit 1884 in der Grube; von 1887-1902 Hauer, dann Steiger. Zittern trat auf in der Hauerzeit. Später verschlimmert.

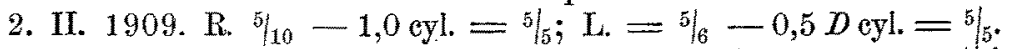

Ganz geringes, vertikales Zittern bei stärkster Blickhebung. $1-\left.1^{1}\right|_{2}{ }^{0}$ latente Diverg. Rechtes Auge Spur höher.

25. V. 1914. Bis jetzt in der Grube. Lebhafte Klagen über Zittern. Trotzdem weder im Hellen, noch im Dunkeln nach Bücken nachweisbar. Dann sagt er: Das Zittern entstehe bei Bewegungen. Er geht einige Male im Dunkelzimmer hin und her. Dabei tritt in der Tat Zittern bei geradem und gesenktem Blick anf, besonders bei mittlerer Linkswendung, lebhaft, vertikal; aber der Anfall ist kurz.

Bemerkenswert ist, dass der Lichtsinn dieser 4 Steiger weit unter, die Grösse über dem Durchschnittswert der übrigen Augenzitterer liegt. Auch hier hat der grösste (4) trotz höheren Alters den besten Lichtsinn. Weiter ist hervorzuheben, dass alle früh, z. T. sehr früh befallen wurden, was ja auch zu erwarten ist, wenn die Veranlagung besonders ungünstig liegt. Endlich ist noch darauf hinzuweisen, dass, abgesehen rom 2. Fall, das Augenzittern bei diesen Steigern ganz gering oder intermittierend war.

\section{Schlussergebnis.}

Der Lichtsinn der Augenzitterer ist im allgemeinen als schlecht zu bezeichnen. Die Annahme, dass eine Herabsetzung des Lichtsinns unter den Ursachen des Augenzit- 
terns eine wichtige Rolle spielt, ist durch die vorhergehenden Statistiken wohl begründet. Es ist aber schon jetzt zu betonen, dass sie keineswegs proportional ist der Schwere, Sehwingungsrichtung und Zahl des Augenzitterus. Sie ist vielmehr nur ein Glied in der Kette der Ursachen.

\section{Beweglichkeitsstörungen.}

a) Lähmungen. Sie kommen für die Ätiologie des Augenzitterns nicht in Betracht. Nur einmal (777) beobachtete ich bei einem 62 jährigen Bergmann mit Augenzittern eine Abducens- und Facialisparese nach Schädelbruch. Das Augenzittern war offenbar viel älter.

b) Concomit. Schielen. Darüber habe ich schon in meiner ersten Abhandlung (160, S. 79) auf Grund ron 195 Fällen berichtet, die ich kurz erwähnen will. Darunter war:

I. 1 Fall von manifestem Auswärtsschielen von $30^{\circ}$ bei hochgradiger Myopie $(=0,5 \%)$.

II. 93 Fälle von latenter Divergenz $=47,7 \%$. Die Untersuchung fand statt auf 50 und $30 \mathrm{~cm}$, weil die Hauer- und Reparaturhauerarbeit in mässiger Entfernung geschieht. Die Abweichung lag:

bei $50 \mathrm{~cm}$ Objektdistanz zwischen 0 und 13 Winkelgraden,

" $30 " \quad$ " 1 " 23 "

III. 94 Fälle mit Horizontal- und Vertikaldivergenz $=48,2 \%$, und zwar:

1. 55 mit positiver Vertikaldivergenz (rechte Gesichtslinie höher) $(=28,2 \%)$.

2. 39 mit negativer Vertikaldivergenz (rechte Gesichtslinie tiefer) $(=20 \%)$.

Die Vertikalablenkung lag bei $50 \mathrm{~cm}$ Objektdistanz zwischen einer „Spur" und 21/2 Winkelgraden.

IV. 7 Fälle von Konvergenz $=3,6 \%$.

a) Manifest 3 Fälle $=1,6 \%$. Darunter 1 Fall von periodischem, akkommodativem Schielen wechselnder Grösse, 1 Fall von geringem und 1 Fall von starkem manifesten Schielen.

b) Latent 4 Fälle $=2,0 \%$. Es handelte sich um ganz geringen Grad. Wenigstens 3 waren mit Höhenschielen verbunden. Die Prüfung des binokularen Sehaktes ist damals leider nicht ausgeführt. Nach dem Befund ist anzunehmen, dass er sicher in 3 Fällen von manifestem Schielen fehlte. Unter meinem neuen Material sind 3 weitere Fälle von manifestem Schielen (ohne binokularen Sehakt). 
a) Fall 711, geb. 13. IX. 1880. Seit 1905 in der Grube. Seit Sept. 1913 wackeln die Grubenlampen. $S$ R. $={ }_{4}^{4}: \mathrm{L} .=7 / 9+0,5 D$. Grösse 167,5. Lichtsinn 29000. Dissociiertes Auswärtsschielen von 30-34\%. Das nicht fixierende Auge schielt nach aussen und oben. Ferner ist gleichsinniger Rucknystagmus nach links vorhanden, beiderseits schräg nach oben aussen. Amplitude links grösser als rechts. Zahl ungefähr $57 \times$ in der Minute. Amplitude und Sehwingungsintervall wechseln. Wenn das rechte Auge einen fernen Punkt ansieht, besteht im allgemeinen kein Rucknystagmus; aber das linke Auge macht dabei langsame Vertikalbewegungen von fast $1 \mathrm{~mm}$ Grösse, bei Verdunkelung nach oben, bei Belichtung nach unten. Fixiert das linke Auge, so tritt der oben geschilderte Rucknystagmus auf, auch bei gesenktem Blick. Bei gehobenem Blick, besonders im Dunkeln und bei vornübergebeugtem Kopf gesellt sich dazu typisches, kleinschlägiges, bald vorübergehendes Augenzittern der Bergleute, rechts rotierend gegen den Uhrzeiger, links sehräg.

b) Fall 863. Fahrsteiger, geb. 30. IV. 1859. 38 Jahre in der Grube. 7-8 Jahre vor der Kohle, dann Beamter. Seit einem Jahr Zittern der Lampen.
3. VI. 1911. R. $+0,5 \mathrm{sph} . \bigcirc+1,75 \mathrm{cyl} .=4 / 7$. L. $+1,0$ sph. $\subseteq+2,5 \mathrm{cyl}=4 / 7$.

Im Tageslicht bei erhobenem Blick Zittern R. $>$ L. Rechts sehräg nach oben anssen, links unbestimmt.

Bei Rechtsfixation anf $50 \mathrm{~cm}$ mit Maddox $3-4^{0}$ Konverg. keine Höhenabweichung, keine Fusionsbewegung.

e) Fall 768 , geb. 16. V. 1876. Seit 1893 in der Grube, vor der Kohle bis 1903, dann am Verbauen, seit einem Jahr Gesteinshauer, Augenzittern seit $7-8$ Jahren.

29. VIII. 1914. Bei starker Senkung des Blickes R. $=$ Finger $4 \mathrm{~m}$, L. $=\left.{ }^{4}\right|_{5}+1 \mathrm{D}$. Grösse $162 \mathrm{~cm}$. R. geringer Strabismus convergens. Fallprobe nicht bestanden bei ruhigen Augen.

Heftiges Augenzittern der Bergleute, R. horizontal, L. Raddrehung.

Da diese 6 Fälle von manifestem Schielen die ganze Ausbeute unter fast 800 Bergleuten mit Augenzittern darstellen, so erscheint es sicher, dass manifestes Schielen mit Authebung des binokularen Sehakts unter den Ursachen des Augenzitterns ohne Belang ist.

Ausserordentlich häufig ist dagegen latentes Auswärtsschielen mit und ohne Vertikalablenkung.

Die ausserordentliche Häufigkeit dieser Lageabweichung hat mich damals zu wichtigen Schlüssen veranlasst. Ich fasste das Augenzittern der Bergleute als eine Ermüdung der gegensinnigen Innervation, der Divergenz (horizontales Zittern) und der Höhenequilibrierung (vertikales Zittern) auf. Die übrigen Formen betrachtete ich als Variationen oder Kombinationen obiger Grundformen. Das Auftreten des Augenzitterns bei erhobenem Blick und die Ruhe bei gesenktem Blick glaubte 
ich mit der Tatsache erklären zu können, dass die Divergenz und da mit die leichtere Ermüdbarkeit mit der Augenhebung wächst ${ }^{1}$ ). Einseitiges Zittern führte ich auf einseitigen Ausgleich einer derartigen Stellungsanomalie zurück.

Dransart, der in seinen früheren Arbeiten nur die Parese der Interni erwähnt hat, verbreitet sich dann später (175 and 176) über den Zustand der ganzen Augenmuskulatur. Er misst nicht die Stellungsanomalie, sondern das Fusionsvermögen an der Überwindung verschieden gerichteter Prismen. Er fand nur einige Fälle von Nystagmus mit übernormalem Fusionsvermögen. Bei der Mehrzahl war er geschwächt. Die Methode ist brauchbar, wenn auch die Ausführungen Dransarts über die Fusionskraft der Recti sup. et infer. theoretisch unhaltbar sind.

Meine erste Statistik über die latenten Lageanomalien ist gross genug, so dass ich das spätere, ganz ähnliche Ergebnis hier iibergehen kann. $\mathrm{Zu}$ bemerken ist aber, dass es, wenn auch selten, Fälle von Nystagmus mit Ortophorie gibt, z. B. ein in 203 erwähnter Bergmann, bei dem weder bei geradem, noch bei gesenktem und gehobenem Blick eine latente horizontale Abweichung vorhanden war. Mein jetziges Urteil über die Bedeutung der latenten Schielablenkungen für die Entstehung des Augenzitterns kann ich erst weiter unten abgeben.

c) Angeborener Nystagmus. Eine Kombination von Nystagmus der Bergleute mit angeborenem Zittern ist sehr selten, wenn man von dem Nystagmus, der bei peripheren Blickrichtungen auftritt, absieht. Ausser dem S. 535 mitgeteilten kann ich nur noch folgenden Fall anführen.

Fall 522, geb, 14. XII. 1872. Seit 1902 in der Grube, vor der Kohle seit 1904. Augenzittern seit 11/2 Jahren. kapsel.

Myopie R. $13 \mathrm{D}$, L. $5 \mathrm{D}$. Beiderseits Trübung der hinteren Linsen-

Bei gesenktem Blick besteht feines angeborenes Ruckzittern in Form von Raddrehnng. Bei Blick nach rechts ist die schnelle Phase nach rechts, bei Blick nach links ist sie nach links gerichtet. In der Horizontalen bei geradem Blick tritt dazu Augenzittern der Bergleute, das viel schneller und von gleichmässigem Ablauf ist. Die Kombination von angeborenem und beruflichem Augenzittern ergibt eine schwer zu definierende Bewegung. Bei mittlerer horizontaler Linkswendung relative Ruhe des Ruckzitterns. Hier

1) Dransart macht sich obige Erklärung auf einen Einwand von Coppez zu eigen, ohne zu erwähnen, dass ich diese Antwort vor ihm schon gegeben hatte. Man vergleiche 160 , S. $82-87,174$, S. $196 ; 175$, s. $28-31$ und 176. 
erscheint das Augenzittern der Bergleute rechts als Raddrehung, links vielleicht auch, vielleicht auch etwas schräg von oben aussen nach unten innen.

\section{Der binokulare Sehakt.}

Bis jetzt ist mir ein Fall von Augenzittern bei Einäugigkeit nach Enucleation nicht zu Gesicht gekommen. Roger (142) beobachtete unter 60 Einäugigen (nach Enucleation) keinen einzigen Augenzitterer, während er sonst $17,5 \%$ mit Augenzittern behaftet fand. Man kann also fragen: Schützt Einäugigkeit oder Verlust des binokularen Sehaktes vor Augenzittern? Sichex ist, dass sich Augenzittern bei Bergleuten entwickeln kann, deren binokularer Sehakt schon vorher oder zeitlebens aufgehoben waren. Dahin gehören z. B. die S. 534 erwähnten 6 Fälle von manifestem Schielen. Ferner 6 Fälle mit einseitiger Blindheit oder so hochgradiger Schwachsichtigkeit, dass an binokulares Sehen nicht zu denken war, die ich $(160$, S. 22-23) erwähnt habe.

Dazu kommen noch folgende Fülle:

a) Fall 591, geb. 2. XI, 1867. Seit 1889 in der Grube. R. A. 1904 nach Schlägerei erblindet. Danach ein Jahr ubber Tage. Später wieder in der Grube als Hauer.

23. IV. 1912 bei mir. Augenzittern angeblich seit $1 / 2$ Jahr. Alkoholiker; allgemeiner Tremor. Grösse $166,5 \mathrm{~cm}$. Lichtsinn 6500 .

R. Hornhaut abgeflacht, narbig. Ange geschrumpft. Der Stumpf begleitet alle Bewegungen des linken Auges und macht sogar Konvergenzbewegungen. Beide Augen zittern lebhaft bei mittlerer Blicksenkung. $O b$ das Zittern hier erst nach der Erblindung des rechten Auges aufgetreten ist, erscheint mir trotz der Angabe des Patienten fraglich. Jedenfalls besteht es weiter.

b) Fall 696 , geb. 6. XII. 1878. 21 Jahre in der Grube. L. Auge immer schlecht.

R. $={ }^{4} l_{5} ;-0,5$ cyl. $=\left.{ }_{4}\right|_{4}$ L. $=$ Finger: $\left.3{ }^{1}\right|_{2} \mathrm{~m}-2,0$ cyl. $={ }^{4} / 36^{*}$ Die Fallprobe wird nicht bestanden.

L. Maculae corneae und Leucoma adbaer. Im Dunkeln starker Lidkrampf. R. ist nach Bücken kein sicheres Zittern nachweisbar. L. spontan deutliches horizontales Zittern bei geradem und gehobenem Blick.

c) Fall 708 geb. 21. VIII. 1865. 37 Jahre in der Grube. Seit 5 Jahren Sehstörung.

R. Finger in $4 \mathrm{~m},+4 D$ etwas besser.

L. $+0,5=4]_{5}$. Grösse 174,7. Lichtsinn 550. Fallprobe bei ruhigen Augen nicht bestanden. Bei starker Hebung geringes Zittern. Nach Bücken viel stärker, diskontinuierlich, beiderseits schräg von oben rechts nach unten links mit Rotation mit dem Uhrzeiger. 
d) Fall 717, geb. 25. II. 1876. 18 Jahre in der Grube, keine Klagen. Grösse $171 \mathrm{~cm}$.

R. = Finger in $2 \mathrm{~m} ;-12 \mathrm{D}=4 / 24 ;$ L. $=4 / 4$ E. Fallprobe wird auch mit Brille nicht bestanden.

Zittern auch bei gesenktem Blick; R. von wechselnder Schwingungsrichtung, rotierend mit Uhrzeiger, vertikal, schräg. L. geringer, schräg.

Ausser diesen machte ich noch bei 45 Augenzitterern die Fallprobe. Sie bestanden sämtlich.

Es ergibt sich somit, dass Mangel an binokularem Sehen bei Augenzittern ziemlich selten ist. Eine Ursache des Augenzitterns liegt also sicher nicht darin.

$\mathrm{Zu}$ bemerken ist noch, dass bei den Fällen von einseitiger Blindheit das Zittern manchmal ganz gering, kaum wahrnehmbar, manchmal auch heftig ist. Das blinde Auge zittert auch, bald stärker, bald weniger als das gute.

\section{Der Befund bei Bergleuten ohne Augenzittern.}

Die Nystagmusforschung in bezug auf die Veranlagung steht auf einem Bein, wenn sie nicht auch augenzitternfreie Bergleute berücksichtigt. Erst der Vergleich der Gesunden mit den Kranken wird uns die richtige Bedeutung der einzelnen Abweichungen erkennen lassen und dem heutigen Wirrwarr der Ansichten ein Ende machen.

Diese Seite der Frage ist bisher sehr vernachlässigt worden. Llewellyn (156) hat einige Kontrolluntersuchungen bezüglich des Alters, der Sehschärfe, Refraktion und Farbe der Augen und der Haare angestellt.

Tch habe in früheren Jahren bei manchem Manne mit hohen Refraktionsfehlern, schlechter Sehschärfe, Maculae corneae, Schielen usw. das Augenzittern vermisst, ohne damals das Material zu sammeln. Mein jetziges Vergleichsmaterial an Gesunden steht dem Augenzitternmaterial an Umfang weit nach, doch glaube ich, dass es schon gewisse Unterschiede deutlich hervortreten lässt und der weiteren Forschung den richtigen $\mathrm{Weg}$ weist.

Ich habe bei meinen Fällen die Diagnose "frei von Augenzittern" gestellt, wenn sie auf Befragen keine Klagen äusserten and die Untersuchung im Hellen und im Dunkeln nach zehnmaligem schnellen Bücken kein Zittern erkennen liess. Da ist es natürlich nicht ausgeschlossen, dass in dem einen oder andern Fall ganz geringes Zittern im ersten Stadium übersehen wurde, oder dass es durch Alkoholgenuss (siehe später) zeitweilig aufgehoben war, oder dass es in 
der Anlage schon vorhanden, erst bei weiterer Fortsetzung der Grubenarbeit zur Entwicklung kommt.

Ausgeschlossen von den folgenden Statistiken sind alle Lente, die weniger als 3 Jahre unter Tage arbeiteten, weil die kürzeste von mir beobachtete Inkubationszeit $\left.2^{3}\right|_{4}$ Jahre beträgt.

Es wurden 61 gesunde Leute untersucht, von denen aber nicht jeder einzeln in allen Rubriken zu finden ist. Was die Herkunft des Materials angeht, so befinden sich darunter manche, die wegen einer Altersbrille zu mir kamen. Einen andern Teil liess ich mir aus dem hiesigen Krankenhaus schicken. Die Schwester erhielt nur die eine Weisung, Leute mit schwächenden Allgemeinkrankheiten auszuschliessen, weil diese möglicherweise das Resultat der Lichtsinnprïfung beeinflussen. Die meisten waren dort wegen Verletzungen der oberen oder unteren Extremitäten ${ }^{1}$ ).

1. Alter der Gesunden.

Beginn des 20. Jahres bis Ende des 24. Jahres 6 Fälle,

\begin{tabular}{|c|c|c|c|c|c|c|c|c|c|}
\hline & \#25. & $"$ & $"$ & $"$ & $"$ & 29. & $"$ & 8 & $"$ \\
\hline & $" 30$. & $"$ & $"$ & $"$ & $"$ & 34. & $"$ & 6 & $"$ \\
\hline & $" 35$. & $"$ & , & $n$ & $"$ & 39. & $"$ & 9 & $\eta$ \\
\hline & $\# 40$ & $"$ & $"$ & $"$ & $"$ & 44. & $"$ & 9 & $"$ \\
\hline & $" 45$. & $"$ & $"$ & $"$ & $"$ & 49. & $"$ & 10 & $"$ \\
\hline & $" 50$. & $"$ & $"$ & $"$ & $"$ & 54. & $"$ & 10 & $n$ \\
\hline & $" 55$. & 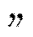 & $"$ & $"$ & $"$ & 59. & $"$ & 3 & 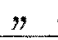 \\
\hline
\end{tabular}

2. Dauer der Grubenarbeit der Gesunden.

Über 3 Jahre bis Ende des 4 . Jahres 4 Fälle,

Beginn des 5. Jahres " " $, 9 . \quad, 7$, ,

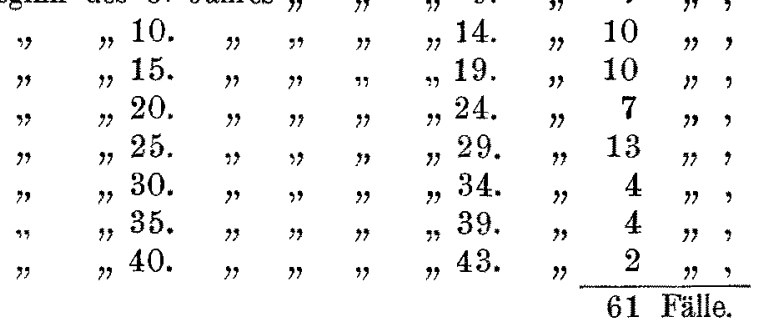

3. Beschäftigungsart zurzeit der Untersuchung.

\begin{tabular}{lrlrll} 
Bremser & 1 & Gesteinshauer & 4 & Fahrhauer & 1 \\
Schlosser unter Tage & 1 & Zimmerhauer & 18 & Schiessmeister & 1 \\
Kohlenhaner & 29 & Förderaufseher & $\mathbf{1}$ & nicht ermittelt & 5 \\
\cline { 3 - 4 } & & & 61
\end{tabular}

1) Das Fehlen dẹs Augenzitterns bei diesen letzteren hat vom Standpunkt der Hypothese Dransarts (vg1. S. 511) eine gewisse Bedeutung. 
1-3 sollen dartun, dass die untersuchten gesunden Bergleute nach Alter, Dauer der Grubenarbeit und Beschäftigungsart der Gefahr des Augenzitterns ausgesetzt waren. Bei den Zimmerhauern, Förderaufsehern, Fahrhauern und Schiessmeistern handelt es sich in der Regel um ältere Bergleute, die in früheren Jahren Hauerarbeit verrichtet haben.

$$
\text { Nationalität der Gesunden. }
$$

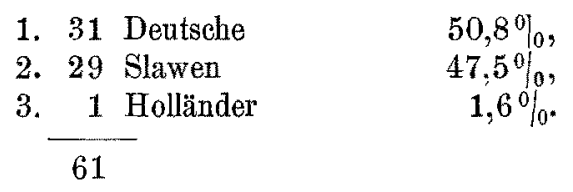

Hier überwiegen also die Deutschen, aber nicht entsprechend ihrem Anteil an der Bevölkerung.

Die Körpergrösse der Gesunden.

\begin{tabular}{|c|c|c|c|c|}
\hline & $153-155$ & einschliesslich & 1 Fall & $1,9^{\circ} \%_{0}$, \\
\hline 2. über & $155-160$ & $"$ & 9 Fälle & $=17,0 \%$ \\
\hline 3. & $160-165$ & $"$ & 5 & $=9,4 \%$, \\
\hline 4. " & $165-170$ & " & 12 & $=22,6 \%$, \\
\hline 5. , & $170-175$ & $n$ & 16 & $=30,2 \%$, \\
\hline 6. " & $175-180$ & $n$ & 8 & $=15,1 \%$, \\
\hline 7. " & $180-185$ & $"$ & 1 Fall & $=1,9 \%$, \\
\hline 8. " & $190 \mathrm{~cm}$ & $"$ & $1 "$ & $=1,9 \%$, \\
\hline
\end{tabular}

Der Kleinste war 153, der Grösste 192,5, der Durchschnitt 168,87 cm.

\section{Der Augenbefund der Gesunden.}

a) Aussere und innere Augenkrankheiten.

Dichter alter Hornhautfleck 1 mal, grosse traumatische Hornhautnarbe $1 \mathrm{mal}$, Erblindung infolge von Leucoma adhaer. $1 \mathrm{mal}$, einseitiges Trachom mit dichtem Pannus und schwerer traumatischer Kieferzertrümmerung $1 \mathrm{mal}$, Amotio retinae seit $5^{1 / 2}$ Jahren $1 \mathrm{mal}$, traumatische Aphakie seit 4 Jahren 1 mal, Katarakt (R. Finger: $30 \mathrm{~cm}$. L. $4 / 12$ ) 1 mal, Rotgrünblindheit 1 mal.

b) Die Sehschärfe ohne Glas auf dem besten Auge:

$$
\begin{aligned}
& \text { 1. Von } 1-5 / 6\left({ }^{4} / 5\right) \text { bei } 35 \text { Fällen }=60,3 \% \text {, } \\
& \text { 2. unter }\left.5\right|_{6}\left(\left.4\right|_{5}\right)-\left.1\right|_{2}, 10,=17,2 \% \text {, } \\
& \text { 3. } " 1 / 2-1 / 10 " 10 "=17,2 \% \text {, } \\
& \text { 4. " }\left.\right|_{10} \quad " 3=5,2 \% \text {, } \\
& \text { Summa } 58 .
\end{aligned}
$$


c) Die Refraktion.

1. Emmetropie bei 8 Fällen $=14,8 \%$,

2. Hypermetropie, bzw. Astigmatismus "24 " $=44,4 \%$, darunter:
a) bis
$0,5 D$
bei 11 Fällen $=20,4 \%$,
b) grösser als $0,5-1,0 \mathrm{D}, 6,=11,1 \%$,
c) $", 1,0-2,0, " 1$ Falle $=1,8 \%$,
d) $" \quad 2,0-3,0 ", 2$ Fällen $=3,7 \%$,
e) " $" 3,0-5,0 ", 4 \Rightarrow=7,4 \%$.

3. Myopie, bzw. Astigmatismus bei 9 Fällen $=16,6 \%$, darunter:
a) grösser als $0,5-1,0 D$ bei 1 Falle $=1,8 \%$,
b) " $" 1,0-2,0, " 3$ Fällen $=5,5 \%$,
c) " " $5,0-10,0 ", 3 \#=5,5 \%$,
d) $", 10,0-15,0, " 2 "=3,7 \%$.

4. Anisometropie

bei 13 Fällen $=24,0 \%$; Summa 54 Fälle.

Tabelle 7. Der Lichtsinn der Gesunden, geordnet nach dem Lichtsinn.

\begin{tabular}{c|c|c|c}
\hline Laufende Nr. & Alter in Jahren & $\begin{array}{c}\text { Dauer der Gruben- } \\
\text { arbeit in Jahren }\end{array}$ & $\begin{array}{c}\text { Lichtsinnwerte bei } \\
\text { der 1. Prüfung in R. E. }\end{array}$ \\
\hline \hline 1 & 51 & 36 & 5000 \\
2 & 43 & 25 & 6250 \\
3 & 28 & & 6500 \\
4 & 30 & & 10000 \\
5 & 52 & 26 & 10000 \\
6 & 35 & 20 & 10500 \\
7 & 51 & 32 & 10526 \\
8 & 41 & 25 & 12500 \\
9 & 20 & 4 & 13250 \\
10 & 44 & 22 & 13500 \\
11 & 45 & 28 & 14200 \\
12 & 50 & 30 & 15500 \\
13 & 54 & 36 & 16664 \\
14 & 53 & 39 & 16664 \\
15 & 26 & 9 & 17000 \\
16 & 46 & 12 & 20000 \\
17 & 49 & 27 & 20000 \\
18 & 58 & 29 & 20800 \\
19 & 31 & & 21600 \\
20 & 41 & 25 & 21800 \\
21 & 32 & & 22222 \\
22 & 45 & 28 & 23500 \\
23 & 39 & 16 & 23750 \\
24 & 30 & 38 & 26800 \\
25 & 39 & 10 & 27000 \\
26 & 52 & 22 & 28000 \\
27 & 50 & & 28500 \\
28 & & & \\
& & & \\
\hline
\end{tabular}




\begin{tabular}{c|c|c|c}
\hline \hline Laufende Nr. & Alter in Jahren & $\begin{array}{c}\text { Dauer der Gruben- } \\
\text { arbeit in Jahren }\end{array}$ & $\begin{array}{c}\text { Lichtsinnwerte bei } \\
\text { der 1. Prüfung in R. E. }\end{array}$ \\
\hline 29 & 39 & 21 & 28571 \\
30 & 37 & 15 & 31000 \\
31 & 43 & 27 & 31000 \\
32 & 34 & 18 & 34200 \\
33 & 38 & 21 & 38600 \\
34 & 22 & 5 & 40000 \\
35 & 32 & 23 & 40000 \\
36 & 49 & 23 & 40000 \\
37 & 50 & 11 & 45000 \\
38 & 34 & 21 & 46000 \\
39 & 29 & 7 & 50000 \\
40 & 37 & 7 & 580000 \\
41 & 25 & 28 & 58000 \\
42 & 35 & & 62000 \\
43 & 24 & 14 & 66500 \\
44 & 45 & $3^{3 / 4}$ & 66667 \\
45 & 40 & 7 & 87000 \\
46 & 42 & 6 & 100000 \\
47 & 20 & $3^{3 / 4}$ & 105000 \\
48 & 28 & & 120000 \\
49 & 24 & 25000 \\
50 & 20 & & \\
51 & & &
\end{tabular}

Tch beschränke mich bei den Gesunden auf eine Prüfung. Ihr Durchschnittswert beträgt 38163 R. E. Es musste mit dem Resultat der ersten Prüfung der Augenzitterer verglichen werden. Es ist anzunehmen, dass das Ergebnis wiederholter Proben ein entsprechend höheres sein würde.

Tabelle 8.

Beziehungen zwischen Alter, Grösse und Lichtsinn bei Gesunden, geordnet nach dem Alter.

\begin{tabular}{|c|c|c|c|c|c|c|}
\hline $\begin{array}{l}\text { Periode } \\
\text { in Jahren }\end{array}$ & $\begin{array}{l}\text { Lauf. } \\
\text { Nr. }\end{array}$ & $\begin{array}{c}\text { Alter } \\
\text { in Jahren }\end{array}$ & $\begin{array}{c}\text { Dauer der } \\
\text { Gruben- } \\
\text { arbeit } \\
\text { in Jahren }\end{array}$ & $\begin{array}{l}\text { Grösse } \\
\text { in } \mathrm{cm}\end{array}$ & Lichtsinn & Durchschnitt \\
\hline $20-24$ & $\begin{array}{l}1 \\
2 \\
3 \\
4 \\
5 \\
6\end{array}$ & $\begin{array}{l}20 \\
24 \\
20 \\
24 \\
22 \\
20\end{array}$ & $\begin{array}{l}3^{3 / 4} \\
7 \\
3^{3 / 4} \\
7 \\
5 \\
4\end{array}$ & $\begin{array}{l}155,5 \\
159,5 \\
168,3 \\
173 \\
178,3 \\
192,5\end{array}$ & $\begin{array}{r}122500 \\
62000 \\
95000 \\
105000 \\
40000 \\
13250\end{array}$ & 72958 \\
\hline $25-29$ & $\begin{array}{l}1 \\
2 \\
3 \\
4 \\
5 \\
6\end{array}$ & $\begin{array}{l}25 \\
28 \\
26 \\
25 \\
28 \\
29\end{array}$ & $\begin{array}{r}6 \\
9 \\
7 \\
11\end{array}$ & $\begin{array}{l}168 \\
168,3 \\
172 \\
173,3 \\
174 \\
180,5\end{array}$ & $\begin{array}{r}120000 \\
100000 \\
17000 \\
58000 \\
6500 \\
50000\end{array}$ & 58583 \\
\hline
\end{tabular}


Beiträge zur Kenntnis des Augenzitterns der Bergleute.

\begin{tabular}{|c|c|c|c|c|c|c|}
\hline $\begin{array}{l}\text { Periode } \\
\text { in Jahren }\end{array}$ & $\begin{array}{l}\text { Lauf. } \\
\text { Nr. }\end{array}$ & $\begin{array}{c}\text { Alter } \\
\text { in Jahren }\end{array}$ & $\begin{array}{c}\text { Dauer der } \\
\text { Gruben- } \\
\text { arbeit } \\
\text { in Jahren }\end{array}$ & $\begin{array}{l}\text { Grösse } \\
\text { in } \mathrm{cm}\end{array}$ & Lichtsinn & Durchschnitt \\
\hline $30-34$ & $\begin{array}{l}1 \\
2 \\
3 \\
4 \\
5 \\
6\end{array}$ & $\begin{array}{l}34 \\
32 \\
31 \\
30 \\
34 \\
32\end{array}$ & 18 & \begin{tabular}{l}
\multicolumn{1}{c}{$?$} \\
168 \\
168,5 \\
170,1 \\
175,5 \\
179
\end{tabular} & $\begin{array}{l}34200 \\
40000 \\
20800 \\
10000 \\
46000 \\
21800\end{array}$ & 28800 \\
\hline $35-39$ & $\begin{array}{l}1 \\
2 \\
3 \\
4 \\
5 \\
6 \\
7 \\
8 \\
9\end{array}$ & $\begin{array}{l}39 \\
37 \\
38 \\
37 \\
39 \\
35 \\
37 \\
35 \\
39\end{array}$ & $\begin{array}{r}16 \\
21 \\
21 \\
16 \\
21 \\
8 \\
15 \\
20 \\
10\end{array}$ & $\begin{array}{l}153 \\
157 \\
158,2 \\
162 \\
164,7 \\
166,5 \\
172 \\
174,7 \\
176\end{array}$ & $\begin{array}{l}23500 \\
50000 \\
38600 \\
27000 \\
28571 \\
58000 \\
31000 \\
10500 \\
26800\end{array}$ & 32663 \\
\hline $40-44$ & $\begin{array}{l}1 \\
2 \\
3 \\
4 \\
5 \\
6 \\
7\end{array}$ & $\begin{array}{l}41 \\
42 \\
44 \\
41 \\
43 \\
43 \\
40\end{array}$ & $\begin{array}{l}25 \\
14 \\
22 \\
25 \\
27 \\
25\end{array}$ & $\begin{array}{l}156 \\
159,5 \\
168 \\
173 \\
175,5 \\
177 \\
179,5\end{array}$ & $\begin{array}{r}12500 \\
87000 \\
13500 \\
21600 \\
31000 \\
6250 \\
66667\end{array}$ & 34073 \\
\hline $45-49$ & $\begin{array}{l}1 \\
2 \\
3 \\
4 \\
5 \\
6\end{array}$ & $\begin{array}{l}49 \\
46 \\
45 \\
45 \\
45 \\
49\end{array}$ & $\begin{array}{l}27 \\
12 \\
28 \\
28 \\
28 \\
23\end{array}$ & $\begin{array}{c}? \\
? \\
164,7 \\
173 \\
175 \\
176\end{array}$ & $\begin{array}{l}20000 \\
18250 \\
22222 \\
14200 \\
66500 \\
40000\end{array}$ & 30195 \\
\hline $50-54$ & $\begin{array}{r}1 \\
2 \\
3 \\
4 \\
5 \\
6 \\
7 \\
8 \\
9 \\
10\end{array}$ & $\begin{array}{l}50 \\
51 \\
54 \\
52 \\
52 \\
51 \\
50 \\
50 \\
53 \\
50\end{array}$ & $\begin{array}{l}30 \\
32 \\
36 \\
22 \\
26 \\
36 \\
38 \\
23 \\
39\end{array}$ & \begin{tabular}{l}
\multicolumn{2}{c}{$\stackrel{2}{155,8}$} \\
164 \\
165,2 \\
165,5 \\
169 \\
171 \\
171,5 \\
172 \\
173
\end{tabular} & $\begin{array}{r}15500 \\
10526 \\
16664 \\
28000 \\
10000 \\
5000 \\
23750 \\
45000 \\
16664 \\
28500\end{array}$ & 19960 \\
\hline $55-59$ & 1 & 58 & 29 & 158,5 & 20000 & 20000 \\
\hline
\end{tabular}

In dieser Statistik ist die Neigung des Lichtsinns, mit steigendem Lebensalter zu fallen, unverkennbar. 
Tabelle 9.

Beziehungen zwischen Lichtsinn und Grösse bei Gesunden, geordnet nach der Grösse.

\begin{tabular}{|c|c|c|c|c|c|c|}
\hline $\mathrm{cm}$ & $\begin{array}{c}\text { Lauf. } \\
\text { Nr. }\end{array}$ & $\begin{array}{c}\text { Alter } \\
\text { in Jahren }\end{array}$ & $\begin{array}{c}\text { Dauer der } \\
\text { Gruben- } \\
\text { arbeit } \\
\text { in Jahren }\end{array}$ & $\begin{array}{l}\text { Grösse } \\
\text { in } \mathrm{cm}\end{array}$ & Lichtsinn & Durchschnitt \\
\hline $151-155$ & 1 & 39 & 16 & 153 & 23500 & 23500 \\
\hline $155-160$ & $\begin{array}{l}2 \\
3 \\
4 \\
5 \\
6 \\
7 \\
8 \\
9\end{array}$ & $\begin{array}{l}20 \\
50 \\
41 \\
37 \\
38 \\
58 \\
42 \\
42\end{array}$ & $\begin{array}{l}3^{3 / 4} \\
30^{4} \\
25 \\
21 \\
21 \\
29 \\
7 \\
14\end{array}$ & $\begin{array}{l}155,5 \\
155,8 \\
156 \\
157 \\
158,2 \\
158,5 \\
159,5 \\
159,5\end{array}$ & $\begin{array}{r}122500 \\
10526 \\
12500 \\
50000 \\
38600 \\
20000 \\
62000 \\
87000\end{array}$ & 50390 \\
\hline $160-165$ & $\begin{array}{l}10 \\
11 \\
12 \\
13\end{array}$ & $\begin{array}{l}37 \\
54 \\
45 \\
39\end{array}$ & $\begin{array}{l}16 \\
36 \\
28 \\
21\end{array}$ & $\begin{array}{l}162 \\
164 \\
164,7 \\
164,7\end{array}$ & $\begin{array}{l}27000 \\
16664 \\
22222 \\
28571\end{array}$ & 28614 \\
\hline $165-170$ & $\begin{array}{l}14 \\
15 \\
16 \\
17 \\
18 \\
19 \\
20 \\
21 \\
22 \\
23\end{array}$ & $\begin{array}{l}52 \\
52 \\
35 \\
44 \\
32 \\
25 \\
20 \\
28 \\
31 \\
51\end{array}$ & $\begin{array}{l}22 \\
26 \\
8 \\
22 \\
6 \\
6 \\
3^{3 / 4} \\
\\
36\end{array}$ & $\begin{array}{l}165,2 \\
165,5 \\
166,5 \\
168 \\
168 \\
168 \\
168,3 \\
168,3 \\
168,5 \\
169\end{array}$ & $\begin{array}{r}28000 \\
10000 \\
58000 \\
13500 \\
40000 \\
120000 \\
95000 \\
100000 \\
20800 \\
5000\end{array}$ & 49030 \\
\hline $170-175$ & $\begin{array}{l}24 \\
25 \\
26 \\
27 \\
28 \\
29 \\
30 \\
31 \\
32 \\
33 \\
34 \\
35 \\
36 \\
37\end{array}$ & $\begin{array}{l}30 \\
50 \\
50 \\
53 \\
26 \\
37 \\
45 \\
41 \\
50 \\
24 \\
25 \\
28 \\
35 \\
45\end{array}$ & $\begin{array}{r}38 \\
23 \\
39 \\
9 \\
15 \\
28 \\
25 \\
\\
7 \\
7 \\
7 \\
\\
20 \\
28\end{array}$ & $\begin{array}{l}170,1 \\
171 \\
171,5 \\
172 \\
172 \\
172 \\
173 \\
173 \\
173 \\
173 \\
173,3 \\
174 \\
174,7 \\
175\end{array}$ & $\begin{array}{r}10000 \\
23750 \\
45000 \\
16664 \\
17000 \\
31000 \\
14200 \\
21600 \\
28500 \\
105000 \\
58000 \\
6500 \\
10500 \\
66500\end{array}$ & 32443 \\
\hline $175-180$ & $\begin{array}{l}38 \\
39 \\
40 \\
41 \\
42 \\
43 \\
44 \\
45\end{array}$ & $\begin{array}{l}43 \\
34 \\
39 \\
49 \\
43 \\
22 \\
32 \\
40\end{array}$ & $\begin{array}{r}27 \\
10 \\
23 \\
25 \\
5\end{array}$ & $\begin{array}{l}175,5 \\
175,5 \\
176 \\
176 \\
177 \\
178,3 \\
179 \\
179,5\end{array}$ & $\begin{array}{r}31000 \\
46000 \\
26800 \\
40000 \\
6250 \\
40000 \\
21800 \\
66667\end{array}$ & 34814 \\
\hline $180-185$ & 46 & 29 & 11 & 180,5 & 50000 & 50000 \\
\hline $190-195$ & 47 & 20 & 4 & 192,5 & 13250 & 13250 \\
\hline
\end{tabular}


Motilitätsstörungen bei Gesunden.

Concomitierendes Schielen.

1. Horizontaldivergenz.

a) Manifest 2 Fälle.

b) Latent $12 "$, und zwar:

\begin{tabular}{c|c|c}
\hline $\begin{array}{c}\text { Abstand in Prismen- } \\
\text { graden }\end{array}$ & $\begin{array}{c}\text { Objektdistanz } 50 \mathrm{~cm} \\
\text { Zahl der Fäle }\end{array}$ & $\begin{array}{c}\text { Objektdistanz } 30 \mathrm{~cm} \\
\text { Zahl der Fälle }\end{array}$ \\
\hline \hline $1 / 2$ & 2 & \\
1 & 2 & 1 \\
3 & 4 & 3 \\
4 & & 2 \\
5 & 1 & 2 \\
6 & 2 & 2 \\
7 & & 1 \\
8 & & 1 \\
9 & & \\
11 & &
\end{tabular}

2. Horizontal- und Vertikaldivergenz.

a) Positive Vertikaldivergenz 13 Fälle,

b) Negative

$15 "$, und zwar:

\begin{tabular}{|c|c|c|c|c|}
\hline $\begin{array}{l}\text { Abstand in } \\
\text { Prismengrad. }\end{array}$ & $\begin{array}{l}\text { Objektdist. } 50 \mathrm{~cm} \\
\text { Zahl der Falle }\end{array}$ & $\left|\begin{array}{c}\text { Objektdist. } 30 \mathrm{~cm} \\
\text { Zahl der Fälle }\end{array}\right|$ & $\begin{array}{l}\text { Abstand in } \\
\text { Prismengrad. }\end{array}$ & $\begin{array}{l}\text { Objektdist. } 50 \mathrm{~cm} \\
\text { Zahl der Fäle }\end{array}$ \\
\hline & \multicolumn{2}{|c|}{ Horizontaldivergenz } & \multicolumn{2}{|c|}{ Positive Vertikaldivergenz } \\
\hline $\begin{array}{r}2 \\
3 \\
4 \\
5 \\
6 \\
7 \\
8 \\
9 \\
10 \\
11 \\
12 \\
14\end{array}$ & $\begin{array}{l}2 \\
2 \\
2 \\
2 \\
2 \\
2 \\
1 \\
\text { Horizonta }\end{array}$ & \begin{tabular}{|r|}
1 \\
1 \\
1 \\
1 \\
1 \\
2 \\
2 \\
1 \\
1 \\
1 \\
1
\end{tabular} & $\begin{array}{l}\text { Spur } \\
1 / 2 \\
1 \\
1^{1 / 2} \\
\end{array}$ & . \\
\hline $\begin{array}{r}0 \\
1 / 2 \\
1 \\
2 \\
3 \\
4 \\
5 \\
6 \\
7 \\
8 \\
9 \\
10 \\
11 \\
15\end{array}$ & $\begin{array}{l}\frac{1}{2} \\
\frac{1}{3} \\
\frac{3}{2} \\
\frac{4}{2} \\
\frac{2}{-} \\
-\end{array}$ & $\begin{array}{l}- \\
2 \\
1 \\
1 \\
1 \\
2 \\
1 \\
2 \\
1 \\
1 \\
1 \\
2\end{array}$ & $\begin{array}{l}\text { Spur } \\
1^{1 / 2} \\
1^{1 / 2}\end{array}$ & $\begin{array}{l}2 \\
\dot{8} \\
4 \\
1\end{array}$ \\
\hline
\end{tabular}

v. Graefe's Archir für Ophthalmologie. LXxxix. 3. 
3. Horizontalkonvergenz.

a) Manifest (mit rotat. Rucknystagmus) 1 Fall.

b) Latent 3 Fälle. (Auf $50 \mathrm{~cm} \mathrm{1/2-3} \mathrm{Prismengrade.)}$

4. Horizontalkonvergenz und negative Vertikaldivergenz 2 Fälle. Höhenablenkung 1 mal eine Spur, 1 mal $1^{\circ}$.

Der binokulare Sehakt.

Er war $8 \mathrm{mal}$ aufgehoben wegen Pannus trachomatosus, Leucoma adhaerens (2 mal), Katarakt, Aphakie, Strabismus divergenz (2 mal), Strabismus convergenz. Weiter wurde bei 21 Mann die Fallprobe gemacht. Sie bestanden sämtlich.

\section{Rü.ckblick.}

Der Vergleich der Kranken und Gesunden hat zwar bemerkenswerte Unterschiede ergeben, aber sie sind nicht derart, dass man einem bestimmten körperlichen Fehler ausschliesslich die Entstehung des Augenzitterns zur Last legen könnte. Wir stossen fast in jeder Statistik auf starke Gegensätze, z. B. gute und schlechte Sebschärfe, hohen und niedrigen Lichtsinn, grosses und kleines Körpermass. Es liegt also die Vermutung nahe, dass die Veranlagung zum Augenzittern durch eine Vereinigung von körperlichen Mängeln gebildet wird.

Was äussere und innere Augenkrankheiten, Sehschärfe und Refraktion angeht, so haben meine Untersuchungen an einer hinreichend Lichrsinn-

Durchschnitt

R.E.

80000

70000

60000

50000

40000

30000

20000

10000

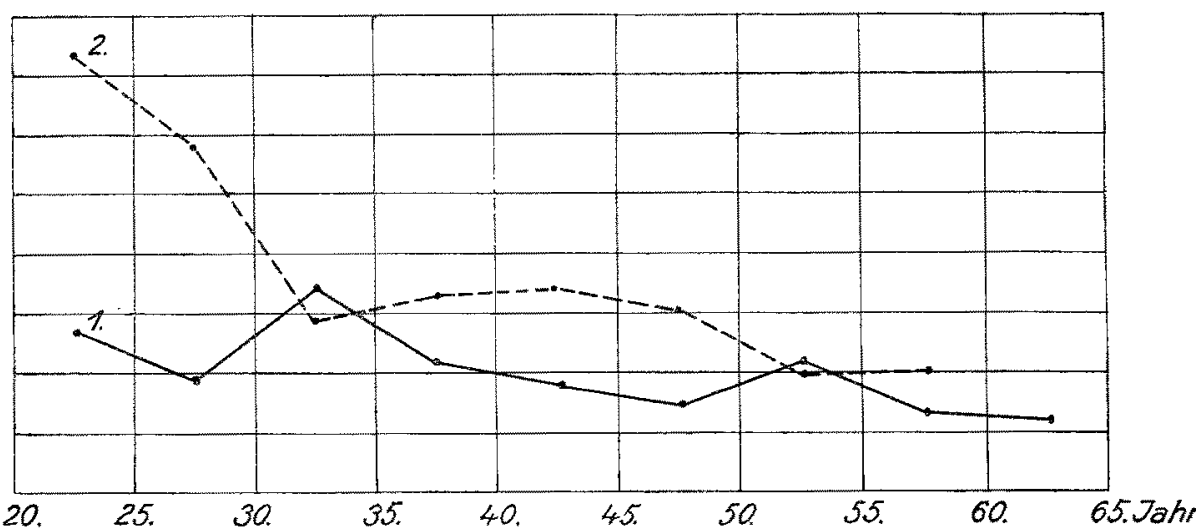

Fig. 10. Beziehungen zwischen Lichtsinn und Lebensalter bei Augenzitterern (1) und Gesunden (2).

grossen Zahl ron Augenzitterern gezeigt, dass es sich da nicht um ein minderwertiges Augenmaterial handelt. Die Augenzitterer stehen 
in diesen Punkten teilweise noch günstiger da, als die Gesunden. Ich glaube also, dass die obigen Mängel für die Erklärung des Augenzitterns nicht viel ergeben.

Ganz anders ist es beim Lichtsinn, weshalb es zweckmässig ist, die Ergebnisse einander gegentiber zu stellen.

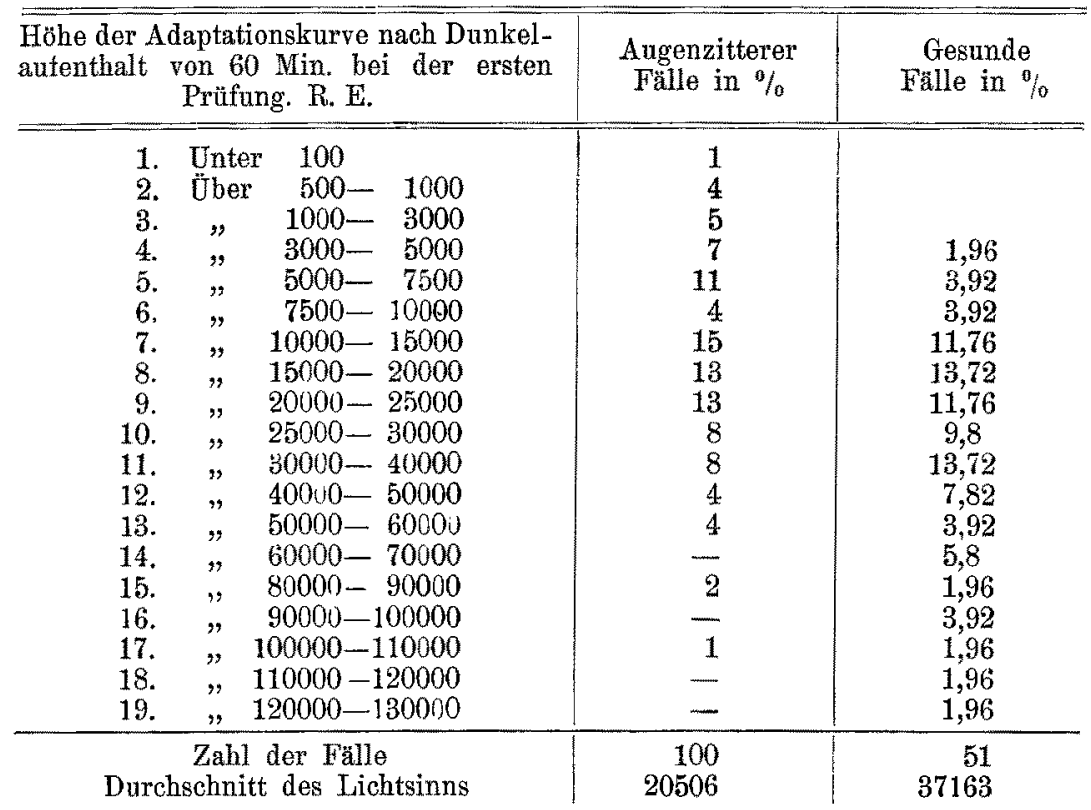

Die ganz niedrigen Kurvenwerte unter 3000, die bei Augenzittern $10 \%$ der Gesamtheit ausmachen, kommen bei Gesunden nicht vor. Während bei den Werten unter 15000 R. E. die Augenzitterer stärker vertreten sind, überwiegen bei den höheren die Gesunden, so dass der Durchschnittswert bei letzteren fast doppelt so gross ist, als bei den Kranken. Die Gegenüberstellung der Lichtsinnkurven in den verschiedenen Lebensaltern gibt folgendes Bild:

\begin{tabular}{|c|c|c|c|c|}
\hline \multirow{2}{*}{$\begin{array}{l}\text { Lebensalter } \\
\text { in Jahren }\end{array}$} & \multicolumn{2}{|c|}{ Augenzitterer } & \multicolumn{2}{|c|}{ Gesunde } \\
\hline & Zahl der Fälle & $\begin{array}{c}\text { Durchschnitt des } \\
\text { Lichtsimns }\end{array}$ & Zahl der Fälle & $\begin{array}{c}\text { Durchschnitt des } \\
\text { Lichtsinns }\end{array}$ \\
\hline $20-24$ & 3 & 27303 & 6 & 72958 \\
\hline $25-29$ & 5 & 19010 & 6 & 58583 \\
\hline $30-34$ & 14 & 34495 & 6 & 28800 \\
\hline $35-39$ & 14 & 21650 & 9 & 32663 \\
\hline $40-44$ & 24 & 17727 & 7 & 34073 \\
\hline $45-49$ & 25 & 14228 & 6 & 30195 \\
\hline $50-54$ & 13 & 21773 & 10 & 19960 \\
\hline $55-59$ & 1 & 12700 & 1 & 20000 \\
\hline $60-64$ & 1 & 11700 & - & - \\
\hline
\end{tabular}

Die hieraus abgeleitete Kurve (Fig. 10) zeigt, dass der Lichtsinn 
mit dem Lebensalter bei Augenzitterern (1) und Gesunden (2) beträchtlich sinkt. Die Kurve der Augenzitterer ist aber durchschnittlich bedeutend niedriger. Am grössten ist der Unterschied zwischen 20 und 30 Jahren. Wenn Bergleute in diesem frühen Alter bereits von Augenzittern befallen werden, so muss ihre Veranlagung besonders stark sein. Da nun ihr Lichtsinn so tief unter dem ihrer gesunden Altersgenossen liegt, so ist man berechtigt, diesem die Schuld beizumessen. Zweimal sinkt die Kurve der Gesunden unter die der Augenzitterer. In der Periode von 30-34 Jahren finden sich unter den Gesunden 2 Fälle mit niedrigem Lichtsinn (Tab. 8, Nr. 3 und 4) bei Auswärtsschielen, das meines Erachtens nicht zu Augenzittern neigt (siehe unten). Ferner liegen die Kurven jenseits des 50. Jahres nahe beieinander. In dieser Zeit kann sich die Wirkung der Veranlagung weniger offenbaren, weil die Leute die Hauarbeit mit der leichteren Zimmerarbeit zu vertauschen pflegen. Die Bedeutung des Lichtsinns wird auch durch einen kurzen Hinweis auf die Arbeitsbedingungen verständlich. In England, wo man Gruben mit Kerzen, Fackeln und Sicherheitslampen vergleichen kann, haben sich die Augenärzte 1912 in Oxford einstimmig dahin geäussert, dass schlechte Beleuchtung die Ursache des Augenzitterns sei. Dr. Court hatte bereits 1891 folgende Statistik veröffentlicht:

Unter 524 Bergleuten, die mit Sicherheitslampen arbeiteten, waren 160 Fälle von Augenzittern,

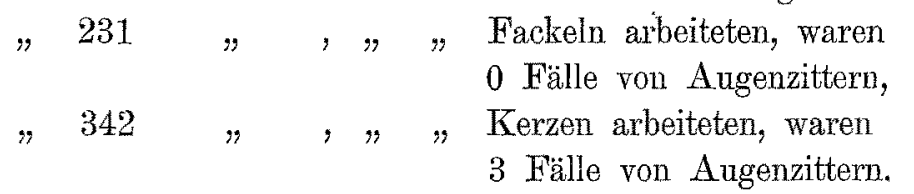

Die Leuchtkraft einer Sicherheitslampe ist nach Llewellyn (165, S. 55) selten grösser als 0,5 Kerzenstärke. Unter Berïcksichtigung aller Umstände muss man die Beleuchtung in einem Bergwerk mit Kerzen 5-10 mal höher schätzen, als in einem solchen mit Sicherheitslampen (165, S. 88). Wenn in diesem, relativ zwar grossem, absolut aber geringen Unterschied der Beleuchtung die äussere Ursache des Augenzitterns enthalten ist, so muss es erlaubt sein, die innere Ursache des Augenzitterns im Lichtsinn zu suchen. Die persönlichen Schwankungen des Lichtsinns entsprechen den Verschiedenheiten der Beleuchtung der Grube mit Sicherheitslampen und Kerzen.

Wer den Einfluss der Grubenbeleuchtung auf das Sehorgan richtig wïrdigen will, muss nicht das Licht der Flammẻ, sondern das von der bearbeiteten Kohlenstelle zurückgeworfene Licht in Betracht 
ziehen. Da nach Llewellyn die Kohle 86-97\% des auffallenden Lichtes verschluckt, so muss sich der Bergmann bei der Arbeit mit einem äusserst geringen Bruchteil einer Kerzenstärke begnügen. Im Nagelschen Adaptometer ist die grösstmögliche Beleuchtungsstärke der Milchglasplatte $=1,45$ Meterkerze. Wer also einen relativen Empfindlichkeitswert von 100000 erreicht, vermag noch $\frac{1}{8000} \cdot \frac{1}{1000}$ ader den 8 Mill. Teil von 1,45 Meterkerzen wahrzunehmen. Ein Mann mit schlechtem Lichtsinn steht aber viel ungünstiger da.

Das Körpermass. Wer der Flötzhöhe einen Einfluss auf die Entstehung beimisst, kann an der Körpergrösse nicht achtlos vorbeigehen. Die Grössenstatistik der Kranken und Gresunden lässt keinen deutlichen Unterschied erkennen. Die Durchschnittsgrösse der Gesunden übertrifft die der Kranken sogar noch um $1 / 2 \mathrm{~cm}$. Trotzdem messe ich der Grösse eine gewisse, wenn auch untergeordnete Bedeutung bei, aus folgenden Gründen:

Stellt man Lichtsinn und Grösse in Beziehung zueinander, so erhält man nachstehende Gruppierung:

\begin{tabular}{|c|c|c|c|c|}
\hline $\begin{array}{l}\text { Körpermass } \\
\text { in } \mathrm{cm}\end{array}$ & $\begin{array}{r}\text { Augen } \\
\text { Zahl der Fälle }\end{array}$ & $\begin{array}{l}\text { nzitterer } \\
\text { Durchschnitt des } \\
\text { Lichtsinns. R. E }\end{array}$ & Ges & $\begin{array}{l}\text { sunde } \\
\text { Durchschnitt des } \\
\text { Lichtsinns. R. E }\end{array}$ \\
\hline $\begin{array}{cl} & 151-155 \\
\text { Über } & 155-160 \\
\Rightarrow & 160-165 \\
" & 165-170 \\
" & 170-175 \\
" & 175-180 \\
" & 180-185 \\
" & 190-192,5\end{array}$ & $\begin{array}{r}3 \\
8 \\
20 \\
34 \\
25 \\
7 \\
3 \\
-\end{array}$ & $\begin{array}{l}25000 \\
15737 \\
11660 \\
18933 \\
26049 \\
30177 \\
37100 \\
-\end{array}$ & $\begin{array}{r}1 \\
8 \\
4 \\
10 \\
14 \\
8 \\
1 \\
1\end{array}$ & $\begin{array}{l}23500 \\
50390 \\
23614 \\
49030 \\
32443 \\
34814 \\
50000 \\
13250\end{array}$ \\
\hline
\end{tabular}

Das Ergebuis ist noch besser aus Kurve $11 \mathrm{zu}$ ersehen. Bei den Augenzitterern (1) über $160 \mathrm{~cm}$ steigt die Lichtsinnkurve bis zum Ende

\section{Lichtsinn -}

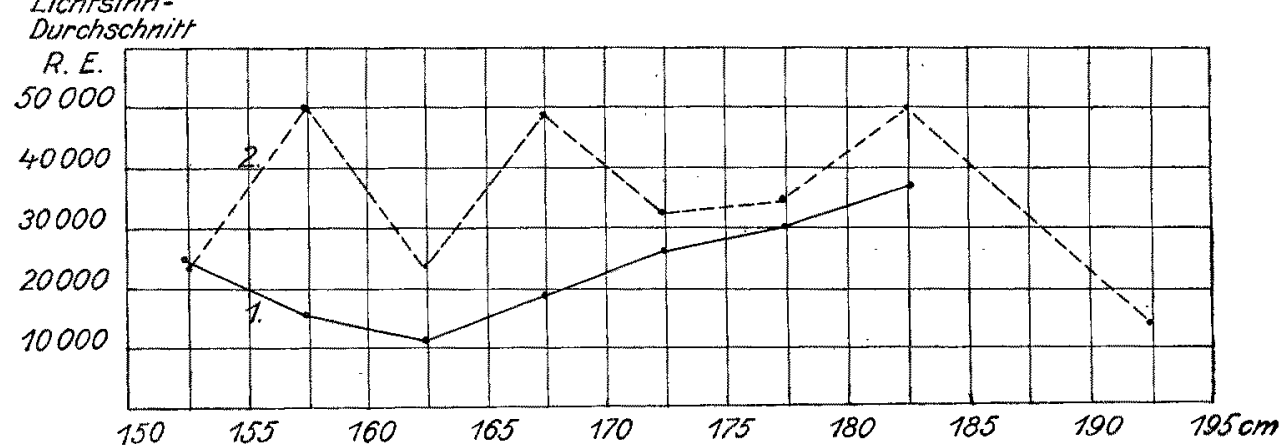

Fig. 11. Beziehungen zwischen Lichtsinn u. Körpergrösse bei Augenzitterern (1) u. Gesunden (2). 
regelmässig an. Die Kurve der Gesunden (2) ist fast ẗberall beträchtlich höher, aber von unregelmässigem Verlauf. Thr Endpunkt wird durch einen aussergewöhnlich grossen Arbeiter mit niedrigem Lichtsinn gebildet, der erst im 20. Lebensjahr und im 4. Jahr der Grubenarbeit stand, also Augenzittern kaum erwerben konnte.

Endlich ist es mir gelungen, gewisse Beziehungen der Grösse zum Krankheitsbild des Augenzitterns nachzuweisen, woron später die Rede sein wird.

Die Bedeutung der Grösse in der Veranlagung ist aber viel geringer als die des Lichtsinns. Das lehrt z. B. anch die Betrachtung der jugendlichen Augenzitterer in der Tab. 4.

Das Körpermass der Fälle unter 30 Jahren liegt unter dem Durchschnitt, aber sie haben einen schlechten Lichtsinn.

Beweglichkeitsstörungen. Folgende Zusammenstellung enthält die Ergebnisse von S. 534 und S. 545.

\begin{tabular}{|c|c|c|c|c|c|c|c|c|}
\hline & \multicolumn{4}{|c|}{195 Augenzitterer } & \multicolumn{4}{|c|}{48 Gesunde } \\
\hline & \multirow{2}{*}{$\begin{array}{c}\text { Zahl } \\
\text { der } \\
\text { Fälle }\end{array}$} & \multirow[b]{2}{*}{$\%$} & \multicolumn{2}{|c|}{$\begin{array}{l}\text { Abweichung in } \\
\text { Prismengraden }\end{array}$} & \multirow{2}{*}{$\begin{array}{l}\text { Zahl } \\
\text { der } \\
\text { Fälle }\end{array}$} & \multirow[b]{2}{*}{$\%$} & \multicolumn{2}{|c|}{$\begin{array}{l}\text { Abweichung in } \\
\text { Prismengraden }\end{array}$} \\
\hline & & & $\begin{array}{c}\text { auf } \\
50 \mathrm{~cm}\end{array}$ & $\mid \begin{array}{c}\text { auf } \\
30 \mathrm{~cm}\end{array}$ & & & $\begin{array}{c}\text { auf } \\
50 \mathrm{~cm}\end{array}$ & $\begin{array}{c}\text { auf } \\
30 \mathrm{~cm}\end{array}$ \\
\hline $\begin{array}{l}\text { 1. Horizontaldivergenz } \\
\text { a) manifest } \\
\text { b) latent }\end{array}$ & $\begin{array}{r}1 \\
93\end{array}$ & $\begin{array}{r}0,5 \\
47,7\end{array}$ & $0-13^{\circ}$ & $\left|1-23^{0}\right|$ & $\begin{array}{r}2 \\
12\end{array}$ & 25 & $1 / 2-7^{0}$ & $1-11^{\circ}$ \\
\hline $\begin{array}{l}\text { 2. a) Horizontal- } \mathrm{a} \text {. positive } \\
\text { Vertikaldivergenz } \\
\text { Horizontaldivergenz } \\
\text { pos. Vertikaldivergenz } \\
\text { b) Horizontal-n. negative }\end{array}$ & 55 & 28,2 & $\begin{array}{c}0-13^{0} \\
\text { Spur-5 }\end{array}$ & $1-17^{0}$ & 13 & 27 & $\begin{array}{c}2-10^{\circ} \\
\text { Spur-20 }\end{array}$ & $2-14^{0}$ \\
\hline $\begin{array}{l}\text { Vertikaldivergenz } \\
\text { Horizontaldivergenz } \\
\text { negat Vertikaldiverg. }\end{array}$ & 39 & 20,0 & $\begin{array}{c}2-13^{0} \\
\operatorname{Spur}-5^{0}\end{array}$ & $2-25^{\circ}$ & 15 & 31,2 & $\mid \begin{array}{c}0-9^{\circ} \\
\text { Spur--1/2 }\end{array}$ & $1-15^{\circ}$ \\
\hline $\begin{array}{l}\text { 3. Kon vergenz } \\
\text { a) manifest } \\
\text { b) latent } \\
\text { kombin. mit negativer } \\
\text { Vertikaldivergenz }\end{array}$ & $\left|\begin{array}{c}3 \\
4 \\
\text { wenig- } \\
\text { stens } 3\end{array}\right|$ & $\begin{array}{l}1,6 \\
2,0\end{array}$ & $\begin{array}{l}2-7^{0} \\
1 / 2-2^{0}\end{array}$ & & $\begin{array}{l}1 \\
5 \\
2\end{array}$ & $\begin{array}{r}2,1 \\
10,4\end{array}$ & $\begin{array}{c}1 / 2-3^{0} \\
\text { Spur-10 }\end{array}$ & \\
\hline
\end{tabular}

Diese Statistik zeigt keine scharf ausgeprägten Unterschiede zwischen Augenzitterern und Gesunden in bezug auf die Schielablenkungen. Günstiger stehen die Augenzitterer da, was manifestes Schielen, sowohl nach innen als nach aussen, angeht. Derartige Fälle machen unter der Gesamtzahl von fast 800 Mann noch nicht $1 \%$ aus. Anders liegt die Sache beim latenten Schielen. Prozentual schwächer sind die Augenzitterer vertreten mit Horizontal + negativer Vertikal- 
divergenz und latenter Konvergenz, viel stärker aber mit latenter Horizontaldivergenz, fast gleich mit Horizontal- und positiver Vertikaldivergenz. Bei allen Abweichungen haben aber die Augenzitterer den Vorrang, was die Grösse der Schielablenkung angeht.

Meine frühere Annahme, dass latente Horizontaldivergenz und Vertikalablenkungen die Entstehung des Augenzitterns begünstigen, ist also bestätigt worden.

Binokularer Sehakt. Derselbe ist weder bei allen Augenzitterern, noch bei allen Gesunden geprüft. Sicher aufgehoben war er unter fast 800 Augenzitterern $16 \mathrm{mal}(=2 \%)$, unter 61 Gesunden $8 \mathrm{mal}$ $(=13 \%$. Vorhandensein des binokularen Sehens scheint mir unter sonst gleichen Bedingungen eher zu Augenzittern zu führen, als sein Fehlen.

\section{Schlussbetrachtung.}

Mit einer Vereinigung obiger Fehler ist die Veranlagung zum Augenzittern noch nicht erschöpft. Denn wir finden einerseits unter den Augenzitterern kleine Leute mit gutem Lichtsinn, die relativ früh erkranken (z. B. Nr. 93 in der Tab. 1), anderseits unter den Gesunden grosse Menschen mit schlechtem Lichtsinn. Da gibt es zwei Möglichkeiten:

1. Die zu Augenzittern veranlagten Leute waren den Arbeitsschädlichkeiten (äussere Ursachen des Augenzitterns) nicht oder noch nicht lange genug ausgesetzt. Es wird also zweckmässig sein, sie unter Aufsicht zu halten, z. B. Nr. 47 in der Tab. 9.

2. Es kommt zu obigen Fehlern noch ein bis jetzt nicht genannter hinzu. Für letzteren, den ich mit $X$ bezeichnen will, besitze ich bis jetzt erst gewisse Anhaltspunkte, die bei Erörterung des Krankheitsbildes besprochen werden sollen.

Die Formel der Veranlagung $=V$, die aus den bis jetzt bekannten Einflüssen Lichtsinn $=L$, Alkoholismus $=A$, Schielablenkungen $=S$, Grösse $=G$ und dem noch dunklen Faktor $X$ besteht, lautet also:

$$
V=\frac{A \cdot S \cdot G \cdot \mathrm{X}}{L} .
$$

Wir können die Kenntnis der Veranlagung noch weiter fördern, wenn wir möglichst solche Augenzitterer untersuchen, bei denen das Schwergewicht nicht auf den Arbeitsbedingungen liegt. Dazu gehören alle jugendlichen Kranken, besonders solche unter 20 Jahren, die mir 
in letzter Zeit nicht zur Verfügung standen. Weiter alle Beamten, soweit sie bereits jahrelang die grobe bergmännische Arbeit hinter sich haben. Endlich alle hartnäckigen Fälle, die ihr Augenzittern jahrelang über Tage noch behalten.

\section{Literaturverzeichnis.}

Ergänzung und Fortsetzung von Nr. 160.

1893. 121) Snell, Le nystagmus des mineurs et la recherche du fen grisou. Question pratique. Journ. d'ocul. du nord de la Françe. Mai.

1907. 122) Bárány, Physiologie und Pathologie des Bogengangapparates. Leipzig und Wien.

123) Horn, Über Dunkeladaptation bei Augenhintergrundserkrankungen. Inaug.-Diss. Tübingen.

124) Nuel, Du nystagmus des houilleurs. Bulletin de l'académie royale de méd. 27. VII.

125) Peters, Is miners' nystagmus of labyrinthine origin? Archives of Ophthalmology. Vol. XXXVI. Nr. 5.

1908. 126) Rutten, Présentation de malades nystagmiques. Société belge d'Ophtalmologie. 26. IV.

1909. 127) Joteyko, La pathogénie du nystagmus des mineurs. Théorie nerveuse. Extrait de revue psychologique fase $\delta$.

128) Sauvineau, Encycl. franc. d'ophtalmologie. VIII.

129) Bárány, Zur Theorie des Bogengangapparates. Zeitschr. f. Sinnesphysiologie.

130) Stassen, Un cas grave de nystagmus. Société médico-chirurgicale de Liége. 1. VII.

131) Bonoit et Stassen, Nystagmus professionnel intermittent greffé sur une irritation anormale du labyrinthe. Société médico-chirurgicale de Liége. 4. XI.

132) Stargardt, Über Störungen der Dunkeladaptation. v. Graefe's Arch. f. Ophth. Bd. LXXIII. S. 77-164. 14. XII.

1910. 133) Benoit et Stassen, Quelques notes sur le nystagmus des houilleurs. Société médico-chirurgicale de Liége. 3. III.

134) Stassen, Quelques notes sur le nystagmus des houilleurs. Extrait du bulletin médical des accidents du travail. 15. III.

135) Behr, Der Reflexcharakter der Adaptationsvorgänge, insbesondere der Dunkeladaptation und deren Beziehungen zur topischen Diagnose und zur Hemeralopie, v, Graefe's Arch. f. Ophth. Bd. LXXV. S. 201 bis 288 .

136) Rutten, Contribution à l'étude pathogénique du nystagmus des houilleurs. Communication faite à la Société belge d'ophtalmologie. Mai.

137) - Présentation d'un houilleur nystagmique. Communication faite à la société belge d'ophtalmologie. 25. IX.

138) Dransart et Famechon, Sur le nystagmus des mineurs dans le bassin houiller du nord de la France pendant des années 1908-1909. Société belge d'ophtrlmologie. 25. IX.

139) Rutten, Présentation dewx houilleurs atteints de névrose nystagmique aiguë provoquée par traumatisme et d'un houilleur nystagmique grave non accidenté. Extrait du bulletin médical des accidents du travail.

140) Nagel, Zwei Apparate für die augenärztliche Funktionsprüfung. Zeitschr. f. Augenheilk. Bd. XVII, 3,

141) Rutten, Contribution à l'étude pathogénique du nystagmus des houil. leurs. Imprimerie médicale et scientifique. L. Severeyns, Bruxelles, rue botanique 34 . 
142) Actes dn II e congrès international de maladies professionnelles. Bruxelles, 10-14. IX.

Séance du 12. IX. Le nystagmus des houilleurs. Discussion: Libert, Roger, Rutten, Lindemann, Dransart, Stassen, Weekers, Declerfayt, Giglioli, Shufflebotham.

Rapports et communications.

Moret, Contribution à la pathogénie du nystagmus des houilleurs. $\mathrm{Nu}$ el, Rapport sur le nystagmus des houilleurs.

Romiée et Thibert, Du nystagmus des houilleurs.

1911. 143) Orlando Orlandini, Studi sulle anomalie dei movimenti associati degli occhi e sul nistagmo. Ospitale civile di Venezia. Pavia.

144) Bielschowski, Über angeborene und erworbene Blickfelderweiterungen. Ophth. Ges. in Heidelberg.

145) L. u. R. Hessberg, Gutachtliche Betrachtung zur Entstehungszeit des sogenannten Nystagmus der Bergleate. Zeitschr. f. Versicherungsmedizin. Nr. 10.

146) Rutten, Contribution à l'étude pathogénique du nystagnaus des houilleurs. L'écho médical. 17. IX.

147) - Quels sont les signes qui différencient le nystagmus des mineurs des autres nystagmus? Société belge d'ophtalmologie. 26. XI. Diskussion: Coppez.

148) - Contribution à l'étude pathogénique du nystagmus des houilleurs. L'écho médical du nord. Lille.

149) Province de Liége, La lutte contre les maladies professionnelles, le nystagmus des houilleurs. Imprimerie industrielle et commerciale, Liége, Math. Thone, rue de la commune 13.

1912. 150) Benoit, L'hyperesthésie du labyrinthe est la cause du nystagmus des ovriers houilleurs. La presse oto-laryngologique, Belge. Mars.

151) $0 \mathrm{hm}$, Neues über das Augenzittern der Berglente. 29. Vers. rhein.westf. Augenärzte in Essen am 9. Juni. Siehe Klin. Monatsbl. f. Augenheilk. Juli.

152) Court, Report of the examinations of the eyes of coal-miners working in colleries. Sheffield.

153) Butler, Miners' nystagmus (The opening address in a discussion on miners' nystagmus at the Oxford ophthalmological congress). 19. VII.

154) Court, Miners' nystagmus. Ebenda.

155) Flworthy, Colour and light in relation to miners' nystagmus. Ebenda.

156) Llewelly $n$, On miners' nystagmus. Ebenda.

157) Cridland, Coal-miners' nystagmus. Ebenda.

158) Browne and Mackenzie, The etiology and treatment of miners' nystagmus. British medical journal. 5. X.

159) Grégoire, Maladies professionnelles, rapport de la commission spéciale. An conseil provincial. 11. X.

160) $0 \mathrm{hm}$, Das Augenzittern der Bergleute, sein Krankheitsbild und seine Entstehung dargestellt an mehr als 500 selbst beobachteten Fällen. v. Graefe's Arch. f. Ophth. Bd. LXXXII, 1. S. 1-98 und Sonderausgabe bei Engelmann, Leiprig. Oktober.

161) Dransart et Vanhoutte, Du nystagmus des mineurs. Discussion: Coppez, Benoit, Moret, van Lint, Moret, Dransart. Bulletin de la société belge d'ophtalmologie. 24 . XI.

162) Coppez, Sur le nystagmus des houilleurs. Journal médical de.Bruxelles. Nr. 49 . 5. XII.

163) Rothfeld, Beitrag zur Kenntnis der Abhängigkeit des Tonus der Extremitätenmuskeln von der Kopfstellung. Versuche mit Narkose. Arch. f. d. ges. Physiol: CXLVIII.

164) Rothfeld, Über den Einfluss akuter und chronischer Alkoholvergiftung auf die vestibularen Reaktionen. Neurol. Zentralbl. Nr. 11.

165) Lilew ellyn, Miners' nystagmus, its causes an prevention. London, Nov. 
166) Court, Defective illumination as the cause of nystagmus and other ocular disorders observed in miners. Sheffield, July.

167) - Miners" nystagmus. Sheffield.

168) Sonntag und Wolff, Anleitung zur Funktionsprüfung des Ohres.

169) Rodger, Miners' nystagmus.

1913. 170) Une maladie professionnelle type: Le nystagmus des houilleurs. Concours médical. Nr. 3. p. 156. 19. I.

171) "Perhandlungen" des Reichstages, 5. II. und des preuss. Abgeordnetenhauses, 1 . III.

172) Diskussion zu 151. Stülp, Hessberg, $0 \mathrm{hm}$. 30. Vers. rhein.-westf, Augenärzte in Düsseldorf am 9 . Februar. Siehe Klin. Monatsbl, f. Augenheilk. März.

173) Butler, Referat, Ophthalmoscope, Februar und April. S. 263.

174) Coppez, Le nystagmus (Tremblement oculaire). Paris, Steinheil.

$175)$ Dransart, Notes sur le nystagmus des mineurs. Société franç. d'opht. Mai.

176) Dransart et Vanhoutte, Notes sur la force de fusion de muscles oculaires. Extrait de l'ophtalmologie provinc. Juin.

177) $0 \mathrm{hm}$, Einige Probleme in der Erforschung des Augenzitterns der Bergleute. Vortrag gehalten in der rhein. Ges. f. wissenschaftl. Forsohung in Bonn. 1. VI.

178) Buys, Contributo allo studio del nistagmo da rotazione. Congresso della società italiana. 17.-21. IX. 1912.

179) Rothfeld, Die Physiologie des Bogengangapparates. Ges. deutscher Naturforscher und Ärzte. IX.

180) - Über die Wirkung einiger Körper aus der Gruppe des Chloroforms auf die vestibularen Augenreflexe. Arch. f. d. ges. Physiol. Bd. CXLIX.

181) $0 \mathrm{hm}$, Ein Beitrag zur Behandiung des Augenzitterns der Berg]eute. Zentralbl. f. prakt. Augenheilk. XII.

182) Une maladie professionnelle type: Le nystagmus des mineurs. Les maladie professionnelles. Le concours médical. p. $15 b$.

183) Bielschowski, Über die relative Ruhelage der Augen. Ophth. Ges. Heidelberg.

184) Lindemann, Nystagmus der Berglente in Herold, Hygiene der Bergarbeiter, Leipzig.

185) Benoit, Syndrome bulbaire des ouvriers honilleurs. Extrait du bulletin de la société belge d'ophtalmologie. Nr. 34. Liége.

186) Bárány und Rothfeld, Untersuchungen des Vestibularapparates bei akuter Alkoholintoxikation und bei Delirium tremens. Deutsche Zeitschr. f. Nervenheilk. Bd. L.

187) Schackwitz, Apparat zur Aufzeichnung der Augenbewegungen beim zusammenhängenden Lesen (Nystagmograph). Zeitschr. f. Physiologie. Bd. LXIII, 7. $\mathrm{X}$.

188) Dransart, Notes sur le nystagmus des mineurs dans le nord de la France.

189) Buys e Hennebert, Morimenti di reazione di origine vestibolare sotto l'influenza della corrente galvanica. Arch. ital. di otologia. XXIV, 3.

190) Katz, Preysing und Blumenfeld, Handbuch der speziellen Chirurgie des Ohres und der oberen Luftwege.

1914. 191) Rothfeld, Über die Beeinflussung der vestibularen Reaktionsbewegungen durch experimentelle Verletzungen der Medulla oblongata. Extrait du bulletin de l'academie des sciences de Cracovie. Janvier.

192) Buys, Une forme spéciale de nystagmus par mouvements brusques de la tête. La presse oto-laryngologique belge. Nr. 1. Janvier.

193) Buys, Du fonctionnement des centres du nystagmus. La clinique. Nr. 2. Janvier.

194) Lafon, La vision des nystagmiques. Annales d'oculistiques. Janvier. 
195) Igersheimer, Über Nystagmus. Klin. Monatsbl. f. Augenheilk. MärzMai.

196) Rutten, Réponse au questionnaire relatif à l'enquête sur le nystagmus des mineurs actuellement ouverte en France par le service des mines. Discussion sur le nystagmus à l'Association belge de médicine sociale, 29. XI. 1913 und 28. III, 1914: Rutten, Glibert, Dewatripont, Capart, Roger.

197) Rothfeld, Das "Oto-Ophthalmotrop", ein Apparat zur Demonstration der vom Ohrlabyrinthe ausgelösten kompensatorischen Augenbewegungen. Berliner klin. Wochenschr. Nr. 6 .

198) Ohm, Die beruflichen Augenverletzungen der Bergleute in einem fünfjährigen Zeitraum. Monatsschr. f. Unfallheilkunde, $\mathrm{Nr} .4$ und 5 , und Sonderausgabe bei $\nabla$ ogel, Leipzig.

199) - Zur graphischen Registrierung des Augenzitterns der Bergleute und der Lidbewegungen. Zeitschr. f. Augenheilk. Heft 1.

200) Paton, Nystagmus with rhytmical head-movement. Proc. of the roy. soc. of med., London, Fol. VII, Nr. 6, sect. of neurol. ophthalm. a. otol. p. 19-84.

201) Pooley, Two cases of miners' nystagmus. Ebenda.

202) Diskussion on nystagmus, ebenda:

Spicer (p. 20), Taylor (29), Scott (33), Llewellyn (42), Makenzie (49), Harmann (56), Coulter (61), Harris (63), Abrahams (64), O'Malley (69), Grimsdale (73), Cridland (74), Mac $\mathrm{Nab}(75)$, Layton (77), Gunn (79), Parsons (81), Jenkins (81), Pooley (82).

1915. 203) Kunz u. Ohm, Über photographische Messung des Augenabstandes und der Pupillen bei Bewegung der Augen von unten nach oben in der mittleren Blickrichtung. v, Gra efe's Arch. f, Ophth. Bd. LXXXIX. 